\title{
CAMA
}

Centre for Applied Macroeconomic Analysis

\section{The Boy Who Cried Bubble: Public Warnings against Riding Bubbles}

\section{CAMA Working Paper 3/2014 January 2014}

Yasushi Asako

Waseda University

\section{Kozo Ueda}

Waseda University and

Centre for Applied Macroeconomic Analysis

\section{Abstract}

Attempts by governments to stop bubbles by issuing warnings seem unsuccessful. This paper examines the effects of public warnings using a simple model of riding bubbles. We show that public warnings against a bubble can stop it if investors believe that a warning is issued in a definite range of periods commencing around the starting period of the bubble. If a warning involves the possibility of being issued too early, regardless of the starting period of the bubble, it cannot stop the bubble immediately. Bubble duration can be shortened by a premature public warning, but lengthened if it is late. Our model suggests that governments need to lower the probability of spurious warnings. 


\section{Keywords}

Riding bubbles, crashes, public warnings, asymmetric information

\section{JEL Classification}

C72, D82, D84, E58, G12, G18

\section{Address for correspondence:}

(E) cama.admin@anu.edu.au

The Centre for Applied Macroeconomic Analysis in the Crawford School of Public Policy has been established to build strong links between professional macroeconomists. It provides a forum for quality macroeconomic research and discussion of policy issues between academia, government and the private sector.

The Crawford School of Public Policy is the Australian National University's public policy school, serving and influencing Australia, Asia and the Pacific through advanced policy research, graduate and executive education, and policy impact. 


\title{
The Boy Who Cried Bubble: \\ Public Warnings against Riding Bubbles*
}

\author{
Yasushi Asako ${ }^{\dagger}$ and Kozo Ueda ${ }^{\ddagger}$
}

January, 2014

\begin{abstract}
Attempts by governments to stop bubbles by issuing warnings seem unsuccessful. This paper examines the effects of public warnings using a simple model of riding bubbles. We show that public warnings against a bubble can stop it if investors believe that a warning is issued in a definite range of periods commencing around the starting period of the bubble. If a warning involves the possibility of being issued too early, regardless of the starting period of the bubble, it cannot stop the bubble immediately. Bubble duration can be shortened by a premature public warning, but lengthened if it is late. Our model suggests that governments need to lower the probability of spurious warnings.
\end{abstract}

Keywords: riding bubbles, crashes, public warnings, asymmetric information

JEL Classification Numbers: C72, D82, D84, E58, G12, G18

${ }^{*}$ The authors are thankful to Gian Luca Clementi, two anonymous referees, Kosuke Aoki, Hidehiko Ishihara, John Morrow, Tomoya Nakamura, Makoto Nirei, Jaume Ventura, Róbert Veszteg and the seminar participants at Hitotsubashi University, Hokkaido University, Waseda University, the CARF (Center for Advanced Research in Finance) Conference, the 19th Decentralization Conference, and the WEAI (Western Economic Association International) Conference.

†Waseda University (yasushi.asako@aoni.waseda.jp)

${ }^{\ddagger}$ Waseda University and Centre for Applied Macroeconomics Analysis (kozo.ueda@waseda.jp) 
There really was a wolf here! The flock has scattered!

I cried out, "Wolf!" Why didn’t you come?

The Boy Who Cried Wolf in Aesop's Fables

\section{Introduction}

History is rife with examples of bubbles and bursts (see Kindleberger and Aliber [2011]). A prime example is the recent financial crisis that started in the summer of 2007; in particular, it reminded policymakers that preventing bubbles is paramount to maintaining financial and economic stability. However, we have limited knowledge of how bubbles arise and how they can be prevented.

Using the Abreu and Brunnermeier (2003) model of riding bubbles, this paper considers the role of public policy in dealing with bubbles, and specifically, whether public warnings can prevent bubbles. Certain recent studies have indicated that asymmetric information creates bubbles. ${ }^{1}$ If only a fraction of agents know that a stock is currently overpriced, they might have an incentive to ride the bubble: They would hold their stock and then disinvest at a higher price ahead of other less-informed investors. However, if all investors were equally well informed on overpriced stocks, they would probably lose by riding the bubble. In this respect, public information is considered important to reduce the degree of asymmetric information and thus, eliminate the bubble.

However, government authorities have been unable to successfully stop bubbles by means of warnings. Kindleberger and Aliber (2011, p.19) state,

One question is whether manias can be halted by official warning-moral suasion or jawboning. The evidence suggests that they cannot, or at least that many crises followed warnings that were intended to head them off.

For example, in February 1929, Paul Warburg, the then Chairman and one of the founders of the Federal Reserve Board (Fed), warned that U.S. stock prices were too high and that

\footnotetext{
${ }^{1}$ See De Long et al. (1990), Allen and Gordon (1993), Allen and Gale (2000), Abreu and Brunnermeier (2002), Scheinkman and Xiong (2003), and Doblas-Madrid (2012).
} 
the situation was similar to the 1907 crisis. Despite the warning, stock prices continued to increase. In December 1996, although Alan Greenspan, the then Chairman of the Fed, warned that the U.S. stock market was "irrationally exuberant," stock prices continued to increase (Kindleberger and Aliber [2011, p.89-90]). Japan encountered a similar challenge during the bubble economy in the late 1980s. Okina et al. (2001, p.422) indicated that the Bank of Japan "had already voiced concern over the massive increase in money supply and the rapid rise in asset prices in the summer of 1986." In fact, Yasushi Mieno, the then Deputy Governor of the Bank of Japan, described the situation as "dry wood" (referring to something that can easily catch fire, implying the risk of high inflation). However, according to Okina et al. (2001, p.430), the Bank of Japan "could not succeed in persuading the public" to stop the growth of the bubble.

Motivated by these policy experiences and debate, this paper examines the effects of public warnings on equilibrium strategies of individual investors, using a simple model of riding bubbles. Namely, we simplify the model of Abreu and Brunnermeier (2003) $)^{2}$ to consider two discrete types of rational investors who have different levels of private informationearly-signal agents and late-signal agents - instead of considering continuously distributed rational investors. As the name implies, early-signal agents receive a private bubble signal earlier than late-signal agents. This simplification not only yields the same riding bubble equilibrium as that in Abreu and Brunnermeier (2003), but also allows the model to be extended.

We introduce public warnings in the model as a public signal. We assume that public warnings are given exogenously; we do not analyze the strategic choice of a government authority to issue warnings. The model also does not answer whether the bubble equilibrium is Pareto-dominated, and hence, it does not provide a clear rationale for government intervention. Despite these limitations, our paper is of value, because to the best of our knowledge, no attempt has been made to theoretically examine the role of public warnings on riding bubbles. We consider two types of public warnings. The first type is issued in a definite range of periods around the starting period of the bubble. In this case, a warning

\footnotetext{
${ }^{2}$ This theory is supported by several empirical and experimental studies, such as those by Temin and Voth (2004) and Brunnermeier and Morgan (2010).
} 
may be delayed, but is always effective: the bubble bursts on the warning date. Moreover, it is noteworthy that the bubble may burst before the warning. Investors know that the bubble bursts on the date of the warning, and hence, they may want to sell earlier. Second, we consider the more general and realistic public warning issued in an indefinite range of periods around the starting period of the bubble. More precisely, it conforms to the Poisson distribution whose mean is equal to the starting period of the bubble. This case encompasses a scenario in which a warning may be issued too early or too late, but more likely, it may be issued around the starting period of the bubble. In this case, while public warnings affect investors' strategies, they cannot stop the bubble immediately. The bubble duration can be shortened by a premature public warning, but lengthened if it is accidentally late.

Whether public warnings help investors deduce their types, namely whether they are early-signal agents or late-signal agents, is key to these results. In the case of definite-range warnings, some investors are able to deduce that other investors were previously aware of the bubble. These late-signal agents recognize that they cannot sell their stock at a high price if they maintain their bubble-riding strategy; therefore, they sell their stock immediately. The bubble then bursts at the warning date. In the case of indefinite-range warnings, investors cannot deduce their types with certainty, but revise their beliefs with regard to their types to some degree by taking Bayes' law into account. For example, agents who receive the public warning after the private signal is issued become more optimistic about the opportunity to sell their stock at a high price. As a result, the warning cannot stop the bubble immediately, and investors extend their bubble-riding duration. This result implies that governments need to lower the probability of spurious warnings in order to enhance the effectiveness of public warnings.

Previous studies have implemented various frameworks to explain bubbles. Classically, bubbles are explained by rational bubble models within a rational expectations framework (Samuelson [1958] and Tirole [1985]). These models are used to analyze the macroimplications of bubbles when bubbles and bursts are given exogenously, investors have symmetric information, and coordination expectation is exogenously assumed. Therefore, these studies did not focus on individuals' strategies. Recently, some models have shown that investors hold a bubble asset because they believe that they can sell it for a higher price in 
the future. These models focus on the microeconomic aspect of bubbles, assuming asymmetric information. Public warnings thus play an important role in mitigating asymmetric information and affecting bubble occurrence. ${ }^{3}$

This paper is structured as follows. Section 2 presents the simple model of riding bubbles. Section 3 derives pure-strategy perfect Bayesian equilibria without public warnings. Section 4 analyzes the effects of public warnings and discusses implications. Section 5 concludes the paper.

\section{The Model}

This section presents the model used to analyze the effects of public warnings, by simplifying the model of Abreu and Brunnermeier (2003). A bubble is depicted as a situation in which the growth rate of the asset price is higher than its fundamental value. At some point during the bubble, investors become aware of its occurrence, but its timing differs across investors: some investors can become aware of the bubble earlier than others. Thus, even though they notice that the bubble has already occurred, they do not know the true starting period of the bubble. Investors may keep their assets even though they know that other investors are also aware of the bubble. Abreu and Brunnermeier (2003) called such an action "riding bubbles." We describe the model below.

Time is continuous and infinite, with periods labeled $t$. Figure 1 depicts the asset price process. From $t=0$ onwards, the asset price $p_{t}$ grows at a rate of $g>0$, that is, the price evolves as $p_{t}=\exp (g t) .{ }^{4} \mathrm{Up}$ to some random time $t_{0}$, the higher price is justified by the

\footnotetext{
${ }^{3}$ It is well known, however, that asymmetric information alone cannot explain bubbles. The key is the no-trade theorem (see Brunnermeier [2001]): investors do not hold a bubble asset when they have common knowledge on a true model, because they can deduce the content of the asymmetric information (Allen et al. [1993] and Morris et al. [1995]). Therefore, some studies have explained bubbles by introducing noise traders (De Long et al. [1990]), heterogeneous belief (Harrison and Kreps [1978], Scheinkman and Xiong [2003]), or principal-agent problems between fund managers and investors (Allen and Gordon [1993], Allen and Gale [2000]).

${ }^{4}$ In Abreu and Brunnermeier (2003), prior to $t=0$, the growth rate of the asset price which coincides with the fundamental value is lower than $g$. This captures the observation that "(h)istorically, bubbles have often emerged in periods of productivity enhancing structural change.” (p. 178). At period 0, the macroeconomic
} 
fundamental value, but this is not the case after the bubble starts at $t_{0}$. The fundamental value grows from $t_{0}$ at the rate of zero, and hence, the price justified by the fundamental value is $\exp \left(g t_{0}\right)$, and the bubble component is given by $\exp (g t)-\exp \left(g t_{0}\right)$, where $t>t_{0}$. The price $(\exp (g t))$ is kept above the fundamental value after $t_{0}$ by behavioral (or irrational) investors. Abreu and Brunnermeier (2003) indicated that such behavioral investors "believe in a 'new economy paradigm' and think that the price will grow at a rate $g$ in perpetuity" $\left(\right.$ p.179). ${ }^{5}$

\section{[Figure 1 Here]}

Like Doblas-Madrid (2012), we assume that $t_{0}$ is discrete as is $t_{0}=0, \eta, 2 \eta, 3 \eta \cdots$, where $\eta>0$ and that it obeys the geometric distribution with a probability function given by $\phi\left(t_{0} / \eta\right)=(\exp (\lambda)-1) \exp \left(-\lambda t_{0} / \eta\right)$, where $\lambda>0$. The expected value of $t_{0}$ is given by $\eta /(1-\exp (-\lambda))$.

There exists a continuum of rational investors of size one, who are risk neutral and have a discount rate equal to zero. A private signal informs them that the fundamental value is lower than the asset price, that is, the fact that the bubble has occurred. The signal, however, does not give information about the true $t_{0}$. Two types of investors exist. A fraction $\bar{\alpha} \in(0,1)$ of them are early-signal agents (type- $E$ ), while the rest, namely, $1-\bar{\alpha}$, are late-signal agents (type- $L$ ). We denote their types by $i=E, L$. Type- $i$ investors receive a private signal at

$$
t_{i}=\left\{\begin{array}{cc}
t_{0} & \text { if } i=E \\
t_{0}+\eta & \text { if } i=L
\end{array}\right.
$$

system receives an exogenous shock, such that the growth rate of the fundamental value becomes higher than that in the previous periods. As they indicate, "(t)his higher growth rate may be viewed as emerging from a series of unusual positive shocks that gradually make investors more and more optimistic about future prospects." (p. 179)

${ }^{5}$ This is a controversial feature in that the price formation process is given exogenously, and behavioral investors play an important role in supporting such a high price. Recently, Doblas-Madrid (2012) used a discrete-time model, and assuming fully rational investors, he showed an implication similar to that of Abreu and Brunnermeier (2003). To simplify our model, we assume the same setup as that of Abreu and Brunnermeier (2003). 
These investors hold assets at period 0. As long as they hold the assets, investors have two choices in each period - to either sell the entire assets or keep them. They cannot buy their assets back. ${ }^{6}$ Ex ante, no investor knows his type. Once an investor receives his private signal at time $t_{i}$, he knows that $t_{0}$ equals either $t_{i}-\eta$ or $t_{i}$, except for the special case of $t_{i}=0$. When $t_{i}=0$, he knows that he is a type- $E$ investor. In the following discussion, we exclude this special case. ${ }^{7}$ The truncated distribution of $t_{0}$ is

$$
\phi\left(\frac{t_{0}}{\eta}=\frac{t_{i}}{\eta}\right)=\frac{\exp (-\lambda \eta)}{1+\exp (-\lambda \eta)}, \phi\left(\frac{t_{0}}{\eta}=\frac{t_{i}}{\eta}-1\right)=\frac{1}{1+\exp (-\lambda \eta)},
$$

and $\phi\left(t_{0} / \eta\right)=0$, for all $t_{0} \neq t_{i}, t_{i}-\eta$. Let $\alpha$ denote the posterior belief that an investor is type- $E$ after he receives a private signal. It is expressed as

$$
\alpha \equiv \frac{\phi\left(\frac{t_{i}}{\eta}\right) \bar{\alpha}}{\phi\left(\frac{t_{i}}{\eta}\right) \bar{\alpha}+\phi\left(\frac{t_{i}}{\eta}-1\right)(1-\bar{\alpha})}=\frac{\bar{\alpha} \exp (-\lambda \eta)}{1-\bar{\alpha}(1-\exp (-\lambda \eta))},
$$

because the fraction of type- $E$ investors is $\bar{\alpha}$. Since $\phi\left(t_{i} / \eta\right)<\phi\left(t_{i} / \eta-1\right), \alpha$ is less than $\bar{\alpha}$.

When $\bar{\alpha}$ of the investors sell their assets, the bubble bursts (endogenous burst), and the asset price drops to the fundamental value $\left(\exp \left(g t_{0}\right)\right)$. Abreu and Brunnermeier (2003) interpreted $\bar{\alpha}$ as the "absorption capacity of behavioral traders," and if the selling pressure of rational investors exceeds it, the asset price plunges, since the effect of behavioral investors on the high growth rate of the price is cancelled out by rational investors' arbitrages (p.179). Therefore, if all type- $E$ investors sell their assets, the bubble bursts. We also assume that each investor is a price taker: If investors choose a certain period to sell their assets, the bubble is certain to burst in this period, even if one investor waits longer to sell or sells earlier. If less than $\bar{\alpha}$ investors sell their assets before $t_{0}+\bar{\tau}$, the bubble bursts automatically

\footnotetext{
${ }^{6}$ These assumptions, not employed by Abreu and Brunnermeier (2003), are not critical. In their Lemma 1 (p.183), Abreu and Brunnermeier (2003) showed that investors do not purchase or sell partially, and hence, the assets are actually bound at 0 or 1 at equilibrium. In Corollaries 1 and 2 (p.183), Abreu and Brunnermeier (2003) showed that investors never buy their assets back at equilibrium. To simplify, we just assume two outcomes.

${ }^{7}$ Only investors who receive the private signal in period 0 can deduce their type. In equilibrium, such type- $E$ investors choose a duration to keep the assets, such that (i) they can sell before investors who receive the private signal at $\eta$, and (ii) investors who receive the private signal at $\eta$ do not have an incentive to sell earlier than or at the same time as these type- $E$ investors.
} 
at $t_{0}+\bar{\tau}$ (exogenous burst). We assume that $\bar{\tau}>\eta$ and that $\bar{\tau}$ is $k \eta$ periods later than $t_{0}$, where $k$ is an integer and $k>1$.

We also assume that $\bar{\alpha} \leq 1 / 2$ (which means $\alpha<1 / 2$ ). The fraction of type- $L$ investors is higher than that of type- $E$ investors. In other words, if all type- $L$ investors $(1-\bar{\alpha}$ investors $)$ sell their assets, then the bubble bursts. We also assume that when $1-\bar{\alpha}$ investors or less simultaneously sell their assets before the others, these investors can sell at a high price. On the other hand, if more than $1-\bar{\alpha}$ investors simultaneously sell their assets, they cannot sell at a high price and receive only $\exp \left(g t_{0}\right) \cdot{ }^{8}$ Note that $\bar{\alpha}$ has two meanings: it indicates (1) the fraction of type- $E$ investors and (2) the fraction of investors that would cause the bubble to burst endogenously were they to sell their assets. ${ }^{9}$

All the timings, $t_{0}, t_{i}$, and $t_{0}+\bar{\tau}$, are summarized in Figure 1. At $t_{0}$, a bubble starts, and type- $E$ investors receive a private signal simultaneously, that is, at $t_{i}=t_{0}$. If type- $E$ investors do not sell by $t_{0}+\eta$, type- $L$ investors receive a private signal at $t_{i}=t_{0}+\eta$. When $\bar{\alpha}$ investors sell before $t_{0}+\bar{\tau}$, the bubble bursts endogenously. Otherwise, the bubble bursts exogenously at $t_{0}+\bar{\tau}$.

Let us compare our model with that of Abreu and Brunnermeier (2003) before deriving its equilibria. The most important difference is that in Abreu and Brunnermeier (2003), investors become aware of the bubble sequentially and continuously. On the other hand, our model depicts only two types of investors. Despite this difference, the implication (Proposition 1 below) holds, as it does in Abreu and Brunnermeier (2003). We will revisit this difference in Section 3.2.

Next, we introduce two types of public warnings into this model: (1) definite-range and (2) indefinite-range warnings. ${ }^{10}$ A definite-range (an indefinite-range) warning is issued in a

\footnotetext{
${ }^{8}$ The main implications do not change even if we assume that some fraction of investors can sell at a high price when too many investors sell at the same time $t$. In this case, the expected payoff lies between $\exp \left(g t_{0}\right)$ and $\exp (g t)$.

${ }^{9}$ Even if these two fractions differ, our results do not change provided the following three conditions hold: (1) the fraction of type- $E$ investors is $\bar{\alpha},(2)$ the bubble bursts endogenously when $\alpha^{\prime}(<\bar{\alpha})$ investors sell their assets, and (3) when less than $1-\bar{\alpha}$ investors sell their assets simultaneously and before the others sell, all of them can sell at a high price.

${ }^{10} \mathrm{Abreu}$ and Brunnermeier (2003) also analyzed the effect of uninformative events (Section 6.1). The public warning differs from uninformative events in two points. First, uninformative events do not depend
} 
definite (indefinite) range of periods around the starting period of the bubble $\left(t_{0}\right)$. Detailed settings pertaining to public warnings will be discussed later. Before considering the role of public warnings, we derive the equilibrium of the model excluding public warnings.

In what follows, we concentrate on a symmetric pure-strategy perfect Bayesian equilibrium, consisting of strategies and beliefs in period $t$. An investor's strategy $T\left(t_{i}, t_{W}\right)$ focuses on the timing for selling his asset. This depends on the period in which an investor receives the private signal $\left(t_{i}\right)$, and/or the period of the warning $\left(t_{W}\right)$, if it is issued. An investor's belief that he is type- $E$ in period $t$ is denoted by $\mu_{t}\left(E \mid t_{i}, t_{W}\right)$. This also depends on $t_{i}$ and/or $t_{W}$.

\section{No Public Warning}

First, we obtain the following lemma.

Lemma 1 Investors never sell their assets before they receive a private signal in a symmetric equilibrium.

Proof: Suppose that investors sell their assets before they receive a private signal. In a symmetric equilibrium, all investors sell before type- $E$ investors receive a private signal at $t_{0}=t_{E}$ (and their belief is $\left.\mu_{t}\left(E \mid t_{i}, t_{W}\right)=\bar{\alpha}\right)$. However, as the asset price will surely increase to $\exp \left(g t_{0}\right)$ until $t_{0}$, the investor has an incentive to deviate by keeping his asset longer.

\subsection{Perfect Bayesian Equilibria}

According to Lemma 1 , the investor's strategy $\left(T\left(t_{i}, t_{W}\right)\right)$ is executed after he receives the private signal $T\left(t_{i}\right)=t_{i}+\tau$, where $\tau \geq 0$. There are two types of pure-strategy equilibria. The first is that investors sell the assets at $t_{i}+\tau$ where $\tau<\eta$. In this equilibrium, only type- $E$ investors receive the private signal, and they sell the asset before type- $L$ investors are informed. The second, and more important, type of pure-strategy equilibrium is that on the starting time of the bubble, $t_{0}$. Second, Abreu and Brunnermeier (2003) assumed that events are only observed by investors who become aware of the bubble. Considering the nature of public warnings, we do not make such an assumption. 
investors sell the assets at $t_{i}+\tau$, where $\eta \leq \tau \leq \tau^{*}$. In this equilibrium, both type- $E$ and type- $L$ investors receive a private signal, and they are uncertain about their types when they receive this signal. There exists the upper bound $\tau^{*}$, which marks the upper limit of the time the investors can wait without selling their assets. Investors keep their assets even after all investors are aware of the bubble, that is, they ride the bubble. Such equilibria exist if and only if $\alpha$ is sufficiently high, that is, $\alpha \geq \alpha^{*}$. Here, we define $\tau^{*}$ and $\alpha^{*}$ as follows.

Definition 1 Define $\tau^{*}$ and $\alpha^{*}$ such that

$$
\begin{gathered}
\alpha=\frac{\exp (-g \eta)\left[\exp \left(g \tau^{*}\right)-1\right]}{\exp \left(g \tau^{*}\right)-\exp (-g \eta)}, \text { and } \\
\alpha^{*}=\frac{1-\exp (-g \eta)}{\exp (g \eta)-\exp (-g \eta)}
\end{gathered}
$$

Then, the following proposition is obtained.

Proposition 1 There exists an equilibrium wherein investors sell the asset at $T\left(t_{i}\right)=t_{i}+\tau$, and the bubble bursts at $t_{0}+\tau$. The duration $\tau$ is given by (1) $0 \leq \tau<\eta$ if $\alpha<\alpha^{*}$, (2) $0 \leq \tau \leq \tau^{*}$ if $\alpha \geq \alpha^{*}$ and $\tau^{*}<\bar{\tau}$, and (3) $0 \leq \tau<\bar{\tau}$ otherwise. The investor's belief is $\mu_{t}\left(E \mid t_{i}\right)=\alpha$ at $t \geq t_{i}$.

Proof: See Appendix A.1.

The intuition is as follows. First, there exist equilibria, wherein before type- $L$ investors receive a private signal, type- $E$ investors sell the assets, and the bubble bursts. In other words, investors' strategies are to sell the assets at $t_{i}+\tau$, where $0 \leq \tau<\eta$. None of the type- $E$ investors has an incentive to deviate by selling later, since investors are price takers. The bubble bursts when other type- $E$ investors sell the assets. Also, none of the type- $E$ investors has an incentive to deviate by selling earlier, since the bubble continues to grow, and the price will increase until the other type- $E$ investors sell the assets. Type- $L$ investors do not have an incentive to deviate from the strategy either by selling the assets before they receive the private signal (see Lemma 1). Thus, regardless of the value of $\alpha$, there exists an equilibrium wherein $\tau$ is given by $0 \leq \tau<\eta$.

Second, and more importantly, if the investor's belief that he is type- $E$, namely $\alpha$, is sufficiently high, then there also exist equilibria wherein investors hold the assets even after 
both types of investors receive the private signal. In other words, investors' strategies are to sell the assets at $t_{i}+\tau$, where $\tau \geq \eta$. There is a risk of waiting until $t_{i}+\tau$ if $\tau \geq \eta$. If investors are type- $E$ with probability $\alpha$, they can sell at a high price $\left(\exp \left(g\left(t_{i}+\tau\right)\right)\right)$, but if they are type- $L$ with probability $1-\alpha$, the bubble bursts before they sell (corresponding to the price $\left.\exp \left(g\left(t_{i}-\eta\right)\right)\right)$. Therefore, there may be a merit to selling earlier. Notably, if an investor sells $\eta$ periods earlier than $t_{i}+\tau$, he can surely sell before the bubble bursts (at price $\left.\exp \left(g\left(t_{i}-\eta+\tau\right)\right)\right)$, since he can sell the asset with type- $E$ investors even if he is a type- $L$ investor. ${ }^{11}$ However, with this deviation, he needs to forgo the chance to sell the asset at a higher price $\left(\exp \left(g\left(t_{0}+\tau\right)\right)\right)$ with probability $\alpha$. Comparing the payoffs suggests that investors do not have an incentive to deviate from $t_{i}+\tau$ if $\tau \leq \tau^{*}$, where $\tau^{*}$ is defined by (1): The expected payoff from following strategy $t_{i}+\tau^{*}, \alpha \exp \left(g\left(t_{i}+\tau^{*}\right)\right)+(1-\alpha) \exp \left(g\left(t_{i}-\eta\right)\right)$, equals that from the above deviation, $\left.\exp \left(g\left(t_{i}-\eta+\tau^{*}\right)\right)\right)$.

When the investor's belief that he is type- $E, \alpha$, is sufficiently low, such that $\alpha<\alpha^{*}, \tau^{*}$ becomes less than $\eta$. They sell the asset before type- $L$ investors receive a private signal. The equation (2) shows the value of $\alpha$, such that $\tau^{*}=\eta$.

In the following sections, we consider the case wherein the bubble does not burst before the type- $L$ investors receive a private signal, that is, $\tau^{*}$ exceeds $\eta$. We also consider the case wherein the bubble bursts endogenously. To this end, we assume $\alpha \geq \alpha^{*}$ and $\tau^{*}<\bar{\tau}$. Even though we assume $\alpha \leq 1 / 2$, this assumption is not crucial for $\alpha \geq \alpha^{*}$. At most, $\alpha^{*}$ equals $1 / 2$ when $g \eta$ is zero and decreases to zero as $g \eta$ increases.

\subsection{Uniqueness of the Equilibrium}

As stated in Section 1, we simplify the model of Abreu and Brunnermeier (2003) to incorporate public warnings. Without public warnings, the original model yields a unique perfect Bayesian equilibrium, while our simplified model tends toward multiple equilibria. In Abreu and Brunnermeier (2003), investors become aware of the bubble sequentially and continuously. If one investor waits slightly longer, the probability of a burst increases continuously. Thus, there is a unique period until which an investor waits to sell. On the other hand, our

\footnotetext{
${ }^{11}$ Since investors are price takers, one investor's deviation does not affect the asset price; thus, the deviation to $t_{i}-\eta+\tau$ is the most profitable one.
} 
model depicts only two types of investors, and one investor cannot affect the asset price. If all type- $E$ investors choose a certain period to sell their assets, the bubble is certain to burst in that period, even if one investor waits slightly longer. If all type- $E$ investors wait slightly longer, the probability of a burst does not increase, because there is a lag before type- $L$ investors receive the signal. Thus, there exist continuous equilibria with respect to the times to sell. Despite this difference between the models, an important trade-off arises, as noted in Abreu and Brunnermeier (2003): If investors wait longer, the bubble may burst before they sell; however, they may be able to sell their asset at a higher price.

If we suppose that the bubble continues until the upper bound $\left(\tau^{*}\right)$, which is the longest period for which investors do not have an incentive to deviate by selling earlier, we obtain the same result as Abreu and Brunnermeier (2003). Moreover, our result also mirrors that of Abreu and Brunnermeier (2003) when we employ, with some minor changes to our settings, the pure-strategy and symmetric coalition-proof Nash equilibrium introduced by Bernheim, Peleg, and Whinston (1987). ${ }^{12}$ We show this in Appendix B. In the following sections, we focus only on the perfect Bayesian equilibrium, since there is a possibility that a coalitionproof Nash equilibrium does not exist. ${ }^{13}$

\footnotetext{
${ }^{12} \mathrm{~A}$ coalition-proof equilibrium allows players to communicate prior to the game, reaching an agreement to coordinate their actions in a mutually beneficial way. A coalition-proof Nash equilibrium requires that the agreement is not subject to an improving deviation, which is self-enforcing by any coalition of players. A deviation is self-enforcing if there is no further self-enforcing and improving deviation available to a proper subcoalition of players.

${ }^{13}$ It is well known that a coalition-proof Nash equilibrium is a strict concept, because it may not exist depending on the game settings. For example, suppose that $\tau^{*}>\bar{\tau}$. Then, the coalition-proof Nash equilibrium does not exist because of continuous time periods. In a perfect Bayesian equilibrium, investors sell the assets at $t_{i}+\tau$, where $\tau<\bar{\tau}$ when $\tau^{*}>\bar{\tau}$. However, if $\tau<\bar{\tau}$, all investors can improve their expected payoffs by approaching $\bar{\tau}$ by forming a coalition. Thus, neither $\tau<\bar{\tau}$ nor $\tau=\bar{\tau}$ can be a coalition-proof Nash equilibrium, since the bubble crashes at $t_{0}+\bar{\tau}$. Thus, a symmetric coalition-proof Nash equilibrium does not exist.
} 


\section{Public Warnings}

In this section, we consider the effects of two types of public warnings: definite-range and indefinite-range warnings. A definite-range (an indefinite-range) warning is issued in a definite (an indefinite) range of periods around the starting period of the bubble. With regard to a public warning, each investor's strategy $\left(T\left(t_{i}, t_{W}\right)\right)$ depends not only on $t_{i}$ but also on the period $t_{W}$ in which the warning is issued.

\subsection{Definite-Range Warnings}

\subsubsection{Deterministic Warning}

First, we consider a definite-range warning. The typical and simplest example of a definiterange warning is a deterministic warning, where the warning is issued deterministically in a certain period after the bubble starts $\left(t_{W}=t_{0}+\tau_{W}\right)$, and all players know the value of $\tau_{W}>0$. With such a warning, the bubble never continues after the warning is issued.

Suppose $0<\tau_{W}<\tau^{*}{ }^{14}$ Then, the equilibrium involves a situation where investors sell the assets before $t_{i}+\tau_{W}$, and not before $t_{i}+\tau^{*}$. To be precise, the following proposition is obtained.

Proposition 2 Suppose that a public warning is deterministic and $0<\tau_{W}<\tau^{*}$. There exists an equilibrium wherein investors sell the asset at $T\left(t_{i}, t_{W}\right)$. At equilibrium, $T\left(t_{i}, t_{W}\right)=$ $t_{i}+\tau$, where $\tau<\tau_{W}$, if a warning is not issued in time. If a warning is issued, investors sell the assets immediately $\left(T\left(t_{i}, t_{W}\right)=t_{W}\right)$. The beliefs are $\mu_{t}\left(E \mid t_{i}, t_{W}=t_{i}+\tau_{W}-\eta\right)=0$ and $\mu_{t}\left(E \mid t_{i}, t_{W}=t_{i}+\tau_{W}\right)=1$ for all $t \geq \tau_{W}$.

Proof: See Appendix A.2.

The intuition is as follows. If investors receive the warning, they deduce their types from the interval between the public warning and the private signal: it is shorter for type- $L$ $\left(t_{W}-t_{L}=\tau_{W}-\eta\right)$ compared to type- $E\left(t_{W}-t_{E}=\tau_{W}\right)$. Investors who find that they are type- $L$ investors recognize that they cannot sell their assets before the bubble bursts if

\footnotetext{
${ }^{14}$ If $\tau^{*}<\tau_{W}$, the warning is issued too late, and the bubble bursts endogenously before the warning, and thus, the warning never affects the investors' selling decisions.
} 
they choose the same strategy $\left(t_{i}+\tau\right)$ as type- $E$ investors. As a result, they prefer to sell the assets before the other type- $E$ investors do so. The type- $E$ investors guess the type- $L$ investors' strategy. Therefore, all investors have an incentive to sell their assets immediately when they receive the warning. In equilibrium, this warning is never issued, since regardless of investor type, an investor holding the asset until $t_{i}+\tau_{W}$ cannot sell the asset for a high price. As a result, investors' strategies are to sell the assets before the warning is issued, that is, at $t_{i}+\tau$, where $\tau<\tau_{W}$ at equilibrium. They can sell the asset before the bubble bursts only if they are type- $E$. Thus, the bubble bursts before the warning, and hence, the warning is never issued in equilibrium outcomes.

\subsubsection{Discussion}

Our result concerning the deterministic warning does not change even though we consider a more general type of definite-range warning. In Appendix $\mathrm{C}$, we consider a two-period warning, which is issued in either of the two definite periods after the start of the bubble. Such a definite-range warning also yields equilibrium; the bubble bursts immediately if a public warning is issued.

The reason the bubble bursts with a public warning is that it enables the type- $L$ investor to deduce his type, provided the earliest timing in the range of possible warning periods depends on the starting period of the bubble. ${ }^{15}$ Without such warning, the type- $L$ investor never deduces his type, although he is not able to sell at a high price. The type- $L$ investor becomes a victim of the burst, but investors have an incentive to ride the bubble, because exante investors have a chance to be type- $E$ investors and sell at a high price. Such a situation changes if there is a public warning. There are some occasions in which the type- $L$ investor deduces his own type and tries to sell before the type- $E$ investor. As a result, no one has an incentive to hold assets any longer once a warning is issued. These results suggest that public announcements targeted at late-signal investors are important in preventing bubbles. ${ }^{16}$

\footnotetext{
${ }^{15}$ Additionally, the public warning enables the type- $E$ investor to deduce his type if a possible final warning period depends on the starting period of the bubble.

${ }^{16}$ If a deterministic warning is introduced to the model of Abreu and Brunnermeier (2003), late-signal investors, who become aware of the bubble after more than the proportion $\kappa$ of investors are already aware of it, can determine that they received the private signal later than the other investors. Thus, they try to
} 
However, as discussed in Section 1, we did not encounter many cases in which public warnings stopped bubbles. Section 4.2 examines the reason for this historical observation.

\subsection{Indefinite-Range Warnings}

\subsubsection{A Poisson-Distributed Warning}

We consider a Poisson-distributed warning as an indefinite-range warning. Suppose that a warning period $\left(t_{W}\right)$ is discrete as is $t_{W}=0, \eta, 2 \eta, 3 \eta, \cdots$ and obeys the Poisson distribution with mean $t_{0}$. The probability function of the distribution of $t_{W} / \eta$ is given by

$$
f_{\frac{t_{0}}{\eta}}\left(\frac{t_{W}}{\eta}\right)=\frac{\exp \left(-\frac{t_{0}}{\eta}\right)\left(\frac{t_{0}}{\eta}\right)^{\frac{t_{W}}{\eta}}}{\left(\frac{t_{W}}{\eta}\right) !}
$$

for all $t_{W} / \eta=0,1,2, \cdots$. The expected value of $t_{W}$ is $t_{0}$. This type of warning is considered more realistic than that in the previous cases; a warning may be issued either too early or too late, but it is more likely to be issued around the starting period of the bubble, at $t_{0}$. Note that in such cases, the range of possible warning periods $[0, \infty)$ does not depend on $t_{0}$.

We show the following two implications that are distinct from those in the case of a definite-range warning.

1. Because the warning does not allow investors to deduce their type, it cannot stop the bubble immediately.

2. If a public warning is made early (late), investors become less (more) confident about being type- $E$ investors, and the duration of the bubble is shortened (lengthened).

As the abovementioned implications result from the effects of the warning on investors' beliefs, we turn our attention to beliefs in Section 4.2.2.

sell their assets earlier, and the bubble crashes at the same time as the time the public warning is issued. In this respect, we do not obtain Proposition 2 due to our simplification of Abreu and Brunnermeier's (2003) model. 


\subsubsection{Beliefs}

Here, we show that (i) investors cannot deduce their type by a Poisson-distributed warning, and (ii) a public warning makes investors less (more) confident about being type- $E$ investors, if it is made earlier (later) than $t_{i}$.

We consider the belief at $t \geq \max \left\{t_{i}, t_{W}\right\}$, that is, after an investor receives both the private signal and the public warning. The following lemma summarizes the implications.

Lemma 2 Suppose that a public warning is distributed as (3), and $t_{i}>0$. Then, at $t \geq$ $\max \left\{t_{i}, t_{W}\right\}$, an investor's belief is given by

$$
\mu_{t}\left(E \mid t_{i}, t_{W}\right)=\frac{f_{\frac{t_{i}}{\eta}}\left(\frac{t_{W}}{\eta}\right) \alpha}{f_{\frac{t_{i}}{\eta}}\left(\frac{t_{W}}{\eta}\right) \alpha+f_{\frac{t_{i}-\eta}{\eta}}\left(\frac{t_{W}}{\eta}\right)(1-\alpha)}=\left(1+\frac{1-\alpha}{\alpha} \exp (1)\left(1-\frac{\eta}{t_{i}}\right)^{\frac{t_{W}}{\eta}}\right)^{-1} .
$$

The belief increases with $t_{W}$ and decreases with $t_{i}$ when $t_{W}>0$. If $t_{W} \geq t_{i}, \mu_{t}\left(E \mid t_{i}, t_{W}\right) \in$ $(\alpha, 1)$. If $t_{W} \leq t_{i}-\eta, \mu_{t}\left(E \mid t_{i}, t_{W}\right) \in\left[(1+\exp (1)(1-\alpha) / \alpha)^{-1}, \alpha\right)$.

\section{Proof: See Appendix A.3.}

The intuition is as follows. A public warning is likely to be issued around $t_{0}$, and hence, an early warning (low $t_{W}$ compared with $t_{i}$ ) indicates that $t_{0}$ is likely to be lower. This makes the investor believe that the other investors are more likely to have received the private signal earlier than he did, and hence, he is less confident of being a type- $E$ investor. On the other hand, a late warning (high $t_{W}$ compared with $t_{i}$ ) indicates that $t_{0}$ is likely to be higher. This increases the possibility that the other investors will receive the private signal later than he will, and hence, he is more confident of being a type- $E$ investor. Thus, his revised belief regarding being a type- $E$ investor increases with $t_{W}$. The belief $\left(\mu_{t}\left(E \mid t_{i}, t_{W}\right)\right)$ has the lowest value when either $t_{W}=0$ or $t_{i} \rightarrow \infty$, and it converges to $\mu_{t}\left(E \mid t_{i}, t_{W}=0\right)=$ $(1+\exp (1)(1-\alpha) / \alpha)^{-1} \in(0, \alpha)$.

Lemma 2 suggests that investors are still uncertain about their types, even though they receive both the public warning and the private signal. In the case of the definite-range warning, the type- $L$ investor can deduce his type from the warning, and this is the main reason the bubble bursts immediately after the public warning is issued. However, this is not so with a Poisson-distributed warning. The revised belief, of being a type- $E$ investor, 
may be higher or lower than the belief without the warning $\alpha$, and hence, the duration for which the bubble is ridden may be lengthened or shortened depending on the timing of the public warning.

\subsubsection{Equilibrium}

Here, we characterize equilibria with a Poisson-distributed warning. We consider the case wherein investors observe both the public warning and the private signal, that is, we concentrate on investors' strategies at $t \geq \max \left\{t_{i}, t_{W}\right\} .{ }^{17}$ As discussed previously, if $t_{W}>0$, an investor's belief $\left(\mu_{t}\left(E \mid t_{i}, t_{W}\right)\right)$ depends on $t_{i}$. We call the investor who receives the private signal at $t_{i}$ a "type- $t_{i}$ " investor. We denote type- $t_{i}$ 's timing to sell when he receives the public warning at $t_{W}$ by $T\left(t_{i}, t_{W}\right)=t_{i}+\tau\left(t_{i}, t_{W}\right)$. Then, the following proposition is obtained.

Proposition 3 Suppose that a public warning is distributed as (3). Then, at $t \geq \max \left\{t_{i}, t_{W}\right\}$, a type- $t_{i}$ investor's equilibrium strategy is to sell the asset at $T\left(t_{i}, t_{W}\right)=t_{i}+\tau\left(t_{i}, t_{W}\right)$ such that $\tau\left(t_{i}, t_{W}\right)$ satisfies

$$
\mu_{t}\left(E \mid t_{i}, t_{W}\right) \geq \frac{\exp (-g \eta)\left[\exp \left(g \tau\left(t_{i}-\eta, t_{W}\right)\right)-1\right]}{\exp \left(g \tau\left(t_{i}, t_{W}\right)\right)-\exp (-g \eta)},
$$

and $\tau\left(t_{i}, t_{W}\right)<\bar{\tau}$ for all $t_{i} \in[2 \eta, \infty)$. This investor's belief is given by (4). The value of $\tau\left(t_{i}=\eta, t_{W}\right)$ satisfies $\tau\left(t_{i}=\eta, t_{W}\right) \leq \tau\left(t_{i}=2 \eta, t_{W}\right)+\eta$.

Proof: See Appendix A.4.

The basic method for the proof of Proposition 3 is similar to that for Proposition 1. However, the main difference is that while investors are symmetric regardless of the timing they receive a private signal $\left(t_{i}\right)$ in Proposition 1 , the different timing of $t_{i}$ induces different strategies for investors with a Poisson-distributed warning, due to the differing beliefs depending on $t_{i}$.

\footnotetext{
${ }^{17}$ When $t_{W}<t<t_{i}$, after investors receive the public warning, they have an incentive to wait until they receive the private signal, since the price continues to increase at least until type- $E$ investors receive the private signal. When $t_{W}>t>t_{i}$ and $t_{W}$ is made very late, even though the public warning is not issued yet, investors revise their belief about being type- $E$ investors. In this case, the belief about being type- $E$ investors increases as the delay in providing them the public warning increases.
} 
When a type- $t_{i}$ investor chooses $t_{i}+\tau\left(t_{i}, t_{W}\right)$, there exists a risk in waiting until $\tau\left(t_{i}, t_{W}\right)$, since they cannot sell the assets at a high price if they are type- $L$ investors. Suppose that a type- $t_{i}$ investor is a type- $L$ investor. From the perspective of the type- $t_{i}$ investor, the other type- $E$ investors are type- $\left(t_{i}-\eta\right)$ investors. If the type- $t_{i}$ investor deviates to sell when possible type- $\left(t_{i}-\eta\right)$ investors sell, that is, at $t_{i}-\eta+\tau\left(t_{i}-\eta, t_{W}\right)$, this investor can sell the asset before the bubble bursts and is guaranteed to receive the payoff $\exp \left(g\left(t_{i}-\eta+\right.\right.$ $\left.\left.\tau\left(t_{i}-\eta, t_{W}\right)\right)\right)$. The condition (5) means that no one has an incentive to deviate in this way, that is, the expected payoff by choosing $t_{i}+\tau\left(t_{i}, t_{W}\right), \mu_{t}\left(E \mid t_{i}, t_{W}\right) \exp \left(g\left(t_{i}+\tau\left(t_{i}, t_{W}\right)\right)\right)+$ $\left(1-\mu_{t}\left(E \mid t_{i}, t_{W}\right)\right) \exp \left(g\left(t_{i}-\eta\right)\right)$, is not smaller than that of this deviation, $\exp \left(g\left(t_{i}-\eta+\right.\right.$ $\left.\left.\tau\left(t_{i}-\eta, t_{W}\right)\right)\right)$. If the condition (5) is satisfied for all possible timings of $t_{i}$, it constitutes an equilibrium for $t_{i} \geq 2 \eta$.

\subsubsection{Example}

Intuitively, because the investor's belief $\mu_{t}\left(E \mid t_{i}, t_{W}\right)$ increases with $t_{W}$ and decreases with $t_{i}$, the bubble duration $\tau\left(t_{i}, t_{W}\right)$ seems nondecreasing with $t_{W}$ and nonincreasing with $t_{i}$. Even though such monotonicity does not necessarily hold, we can provide an example of such equilibrium strategies.

Claim 1 Suppose a public warning is distributed as (3), and $2 \eta+\tau^{*}>t_{W}$. Then, at $t \geq \max \left\{t_{i}, t_{W}\right\}$, there exists an equilibrium such that the duration to hold the asset $\left(\tau\left(t_{i}, t_{W}\right)\right)$ is nondecreasing with $t_{W}$ and nonincreasing with $t_{i}$.

The detailed illustration of such an equilibrium appears in Appendix D. Here, we sketch its characteristics in Figure 2. We sort investors' types (i.e., type- $t_{i} \mathrm{~s}$ ) into a smaller number of confidence groups, starting with the least confident group, with the lowest $\mu_{t}\left(E \mid t_{i}, t_{W}\right)$, to the most confident group, with the highest $\mu_{t}\left(E \mid t_{i}, t_{W}\right)$. Because the investor's belief $\mu_{t}\left(E \mid t_{i}, t_{W}\right)$ decreases with $t_{i}$, the least confident group includes investors who receive the private signal at $t_{i}$ close to infinity. We call this group Group 0. Group 0 has the smallest $\mu_{t}\left(E \mid t_{i}, t_{W}\right)$, close to its minimum value $\left((1+\exp (1)(1-\alpha) / \alpha)^{-1}\right)$. Such investors hold the asset for the minimum duration it can be held, namely $T\left(t_{i}, t_{W}\right)=t_{i}+\tau_{0}^{*}$, where $\tau_{0}^{*}$ satisfies 
(5) with equality when $\mu_{t}\left(E \mid t_{i}, t_{W}\right)=(1+\exp (1)(1-\alpha) / \alpha)^{-1} \cdot{ }^{18}$

\section{[Figure 2 Here]}

We then define Group 1, wherein investors receive the private signal earlier than Group 0 and hence have higher $\mu_{t}\left(E \mid t_{i}, t_{W}\right)$. Investors in Group 1 hold the assets until $T\left(t_{i}, t_{W}\right)=$ $t_{i}+\tau_{0}^{*}+\varepsilon \eta$, which is longer than those in Group 0 by $\varepsilon \eta$, where $\varepsilon \in(0,1)$. Sequentially, we define Group $m$ wherein investors hold the assets until $T\left(t_{i}, t_{W}\right)=t_{i}+\tau_{0}^{*}+m \varepsilon \eta$, where $m$ is a nonnegative integer. An important property is that as $m$ rises, investors in Group $m$ receive a private signal earlier; thus, they are more confident of being type- $E$ investors and hold the assets longer (see Figure 2). As $m$ increases, the duration to hold the assets also increases, but it may reach the ceiling determined by $\bar{\tau}$. Therefore, if $\tau_{0}^{*}+m \varepsilon \eta \geq \tau_{0}^{*}+\bar{\tau}$, such investor types sell the assets slightly before $\tau_{0}^{*}+\bar{\tau}$.

This example provides three important implications. First, because investors cannot deduce their type via a warning, it cannot stop the bubble immediately. If $t_{W} \geq t_{i}$ and $t_{i}+\tau_{0}^{*}+m \varepsilon \eta>t_{W}$, then investors hold the assets after the public warning is issued. These results differ from those of the previous cases: the bubble bursts with the public warning when $t_{W} \geq t_{i}$ (Proposition 2).

Second, a public warning makes investors less confident of being type- $E$ investors, if it is issued early. Such a warning shortens the bubble duration, although it cannot stop the bubble immediately. If $t_{W}-t_{i}$ is sufficiently low (largely negative), then the bubble duration shortens and becomes as low as the minimum duration $\tau_{0}^{*}$. This is lower than that without public warning or $\tau^{*}$, as defined by Definition $1 .^{19}$

Third, a public warning makes investors more confident of being type- $E$ investors, if it is issued late. Such a warning lengthens the bubble duration. If $t_{W}-t_{i}$ is sufficiently high (largely positive), the duration becomes $\tau_{0}^{*}+m \varepsilon \eta>\tau^{*}$, longer than that without the public warning or $\tau^{*} .^{20}$

Note, however, that these results do not mean that the government should issue a warning as early as possible. To illustrate this, suppose it is certain that the government issues a

\footnotetext{
${ }^{18}$ To be precise, $\tau_{0}^{*}$ satisfies $\mu_{t}\left(E \mid t_{i}, t_{W}=0\right)=\left(\exp (-g \eta)\left[\exp \left(g \tau_{0}^{*}\right)-1\right]\right) /\left(\exp \left(g \tau_{0}^{*}\right)-\exp (-g \eta)\right)$.

${ }^{19}$ This is because $\alpha>(1+\exp (1)(1-\alpha) / \alpha)^{-1}$.

${ }^{20}$ This is because $\tau^{*}<\bar{\tau}$, which is in line with our assumption.
} 
warning at $t_{W}=0$. Then, the public warning no longer obeys the Poisson distribution with mean $t_{0}$. It contains no useful information about the true $t_{0}$. Once investors realize this, the public warning no longer affects their beliefs. Only when the warning is made earlier accidentally, can the bubble duration be shortened.

\subsection{Summary and Policy Implications}

We summarize the implications of the above results and discuss policy implications. Our results highlight the importance of announcements targeted at late-signal agents in preventing bubbles. Note that unless a warning is issued, type- $E$ investors can sell at a high price. Thus, even though type- $E$ investors deduce their type, this has no consequence on the equilibrium. On the other hand, if type- $L$ investors know their type, they need to change their strategy, because they know that they cannot sell at a high price while maintaining their original strategy. Type- $L$ investors try to sell their assets earlier than type- $E$ investors. Consequently, the bubble bursts immediately when type- $L$ investors deduce their type. The previous models show that type- $L$ investors can deduce their type when the starting period of a warning is dependent on the period when the bubble starts $\left(t_{0}\right)$. Conversely, the starting period of a Poisson-distributed warning is period 0 , which does not depend on $t_{0}$. In this case, there is no chance of type- $L$ investors deducing their type. This is the critical reason a Poisson-distributed warning cannot stop the bubble immediately.

An important aspect with regard to a public warning is whether investors believe it. Even if a government authority issues a warning after a bubble starts, if there is a possibility that the warning has been issued too early, and this too-early timing of the warning may not depend on the bubble period, then the bubble cannot be stopped by the warning. In this respect, using the terminology of Okina et al. (2001), it is critical to reduce type-I rather than type-II errors. Okina et al. (2001) introduced the hypothesis that an economic boom is a transitional process for a new economy. A type-I error corresponds to the erroneous rejection of the hypothesis when it is true, and hence, this error implies that a public warning is issued even though the bubble is yet to occur. On the other hand, a type-II error corresponds to the failure to reject the hypothesis when it is false, and hence, it implies that a public warning is not issued even though the bubble has already occurred. In a Poisson-distributed 
warning, both type-I and type-II errors are serious in that the starting period (period 0) and the final period (close to infinity) of the warning do not depend on the bubble starting period. Between the two, the type-I error - wherein the starting period of the warning does not depend on the bubble starting period-is crucial. The importance of reducing type-I errors suggests that governments need to lower the probability of spurious warnings. In other words, governments must not be like the boy who cried wolf.

Regarding macroeconomic policies to address bubbles, previous literature offers two perspectives. First, some studies cast doubt on the active, preemptive role of macroeconomic policy in bubble prevention. For example, Mishkin (2007) argued that bubbles are difficult to detect and that central banks could cope with bubble bursts by reacting quickly after the collapse of asset prices. This proposal corresponds to a mop-up policy. Second, others call for active, preemptive public interventions. For example, Okina et al. (2001), Borio and Lowe (2002), and White (2006) emphasized the risk of a less aggressive macroeconomic policy resulting in disruptive booms and busts in real economic activity. They argued that identifying financial imbalances is possible. With this motivation, Borio and Lowe (2002) searched for indicators of financial imbalances, such as credit growth and asset price increases, from the perspective of noise-to-signal ratios. Before the crisis, the first view appeared to have dominated the second, but the detrimental effects of the recent financial crisis that started in the summer of 2007 have created many proponents of the second view.

Our model provides an answer from a different perspective. Our model does not specify whether the bubble equilibrium is Pareto-dominated, and hence, it does not contribute to the debate on the desirability of a preemptive policy. Rather, our question is whether such policy is effective in preventing bubbles. The first view (regarding macroeconomic policies to address bubbles) is entirely correct if the type-I error is extremely high: bubbles are impossible or highly difficult to detect. In this case, a preemptive communication policy is not needed. Even more strongly than the first view, our model suggests that, if their premise is correct, public warnings do no harm or good, because they are useless information for investors. Simultaneously, our model does not deny the second view. It is noteworthy, however, that the high risks associated with the type-II error, that is, late policy responses to financial imbalances, do not necessarily support early policy responses. 
Thus, the crux of our results is that for a public warning, the type-I error is more important than the type-II error. Therefore, good bubble indicators need to be constructed on the basis of the type-I error. The indicator presented by Borio and Lowe (2002) is one of several promising and more important attempts, although they weighed type-I and -II errors equally while looking at noise-to-signal ratios.

\section{Conclusion}

This paper examined the effects of public warnings against bubbles by using Abreu and Brunnermeier's (2003) model of riding bubbles as the base. We showed why several warnings were ignored by investors. We found that if a warning is issued in a definite range of periods around the starting period of the bubble, the bubble bursts with it. Moreover, the bubble may burst before the warning. If a warning involves the risk of being issued too early regardless of the starting period of the bubble, then it cannot stop the bubble immediately. While the bubble duration can be shortened by a premature public warning, it can be lengthened if it is accidentally late.

We touch upon two limitations of this paper. One is the lack of attention to government strategies. In our model, warnings are issued exogenously. In reality, the government gathers information, analyzes it, and then communicates whether the asset is overpriced. Another limitation involves a consideration concerning irrational investors. In the model, they are treated implicitly as economic entities who herd and ride bubbles. We intend to incorporate these features in our model in future research.

\section{A Proofs}

\section{A.1 Proof of Proposition 1}

Suppose that all investors sell the asset at $T\left(t_{i}\right)=t_{i}+\tau$, where $0 \leq \tau<\eta$. Then, when a type- $i$ investor receives the private signal at $t_{i}$, the probability that $i$ is a type- $E$ investor is $\mu_{t}(E)=1$ for $t \geq t_{i}$, since the bubble bursts before $t_{0}+\eta$, and only type- $E$ investors receive a private signal. An investor receives the private signal and does not deviate by selling his 
asset at $T\left(t_{i}\right)=t_{i}+\tau^{\prime}$, where $\tau^{\prime}>\tau$, since each investor is a price taker and the bubble bursts at $t_{i}+\tau=t_{0}+\tau$, regardless of one investor's choice. Thus, his payoff decreases from $\exp \left(g\left(t_{0}+\tau\right)\right)$ to $\exp \left(g t_{0}\right)$ due to this deviation. Moreover, the investor does not deviate by selling his asset at $T\left(t_{i}\right)=t_{i}+\tau^{\prime \prime}$, where $\tau^{\prime \prime}<\tau$, since his payoff decreases from $\exp \left(g\left(t_{0}+\tau\right)\right)$ to $\exp \left(g\left(t_{0}+\tau^{\prime \prime}\right)\right)$ due to this deviation. Type- $L$ investors also do not have an incentive to deviate from the strategy by selling the assets before they receive the private signal (see Lemma 1). Thus, no investor has an incentive to sell the asset before receiving a private signal. Hence, $T\left(t_{i}\right)=t_{i}+\tau$, where $0 \leq \tau<\eta$ constitutes an equilibrium regardless of the value of $\alpha$.

Suppose that all investors sell the assets at $T\left(t_{i}\right)=t_{i}+\tau$, where $\tau \geq \eta$. Both investor types receive a private signal; $\mu_{t}(E)=\alpha$ for $t \geq t_{i}$. The expected payoff is $\alpha \exp \left(g\left(t_{i}+\right.\right.$ $\tau))+(1-\alpha) \exp \left(g\left(t_{i}-\eta\right)\right)$. The first term corresponds to the payoff for type- $E$ investors. A type- $E$ investor can sell the asset at the price $\exp \left(g\left(t_{i}+\tau\right)\right)$. This belief is given by $\alpha$. The second term corresponds to the payoff for type- $L$ investors. The bubble bursts before the type- $L$ investor sells, and hence, the price is $\exp \left(g\left(t_{i}-\eta\right)\right)$. This belief is given by $1-\alpha$. There are three possible deviations as the assets could be sold in one of the following periods: (i) $t_{i}+\tau^{\prime} \in\left(t_{i}-\eta+\tau, t_{i}+\tau\right)$, (ii) $t_{i}+\tau^{\prime \prime}>t_{i}+\tau$, and (iii) $t_{i}+\tau^{\prime \prime \prime} \leq t_{i}-\eta+\tau$.

First, suppose that an investor deviates to $t_{i}+\tau^{\prime} \in\left(t_{i}-\eta+\tau, t_{i}+\tau\right)$. For type- $L$ investors, the expected payoff remains $\exp \left(g\left(t_{i}-\eta\right)\right)$, because the bubble bursts at $t_{i}-\eta+\tau$. For type- $E$ investors, the expected payoff decreases from $\exp \left(g\left(t_{i}+\tau\right)\right)$ to $\exp \left(g\left(t_{i}+\tau^{\prime}\right)\right)$. Thus, the investor never deviates in this way.

Second, suppose that an investor deviates to $t_{i}+\tau^{\prime \prime}>t_{i}+\tau$. By this deviation, the bubble bursts before he sells, regardless of his type, since one investor is a price taker. The expected payoff decreases from $\alpha \exp \left(g\left(t_{i}+\tau\right)\right)+(1-\alpha) \exp \left(g\left(t_{i}-\eta\right)\right)$ to $\exp \left(g t_{0}\right)$. Thus, the investor never deviates in this way either.

Third, suppose that an investor deviates to $t_{i}+\tau^{\prime \prime \prime} \leq t_{i}-\eta+\tau$. The expected payoff from this deviation is maximized when he deviates to sell at $t_{i}-\eta+\tau$, and the payoff becomes $\exp \left(g\left(t_{i}-\eta+\tau\right)\right)$, because he can sell his asset at this price with certainty. Comparing the payoffs suggests that the investor does not have an incentive to deviate from $t_{i}+\tau$ if 
$\alpha \exp \left(g\left(t_{i}+\tau\right)\right)+(1-\alpha) \exp \left(g\left(t_{i}-\eta\right)\right) \geq \exp \left(g\left(t_{i}-\eta+\tau\right)\right)$, that is,

$$
\alpha \geq \frac{\exp (-g \eta)[\exp (g \tau)-1]}{\exp (g \tau)-\exp (-g \eta)} .
$$

In (1), we define $\tau^{*}$ such that (6) is satisfied with equality. Because the right-hand side of (6) increases with $\tau$, the investor has an incentive to deviate from $t_{i}+\tau$ if $\tau>\tau^{*}$; he does not deviate if $\tau \leq \tau^{*}$.

This $\tau^{*}$ is subject to two bounds. The first is an exogenous burst. If $\tau^{*} \geq \bar{\tau}$, the bubble bursts at $t_{0}+\bar{\tau}$ exogenously before type- $E$ investors sell the assets at $t_{0}+\tau^{*}$. Thus, if $\tau^{*} \geq \bar{\tau}$, investors sell before $t_{i}+\bar{\tau}$. Second, if $\alpha$ is below a certain threshold, $\tau^{*}$ is lower than $\eta$. The condition (2) in Definition 1 defines $\alpha^{*}$ such that $\tau^{*}=\eta$ if $\alpha=\alpha^{*}$. If $\alpha \geq \alpha^{*}, \tau^{*}$ is larger than or equal to $\eta$, and investors' equilibrium strategies are given by $T\left(t_{i}\right)=t_{i}+\tau$, where $\tau \geq \eta$

\section{A.2 Proof of Proposition 2}

Suppose that a warning is issued at $t_{W}=t_{0}+\tau_{W}$, and consider investors' strategies at $t_{W}$. Suppose that the warning is issued after both type- $E$ and type- $L$ investors have received a private signal, that is, $\eta \leq \tau_{W}$. Then, $\mu_{t}\left(E \mid t_{i}, t_{W}=t_{i}+\tau_{W}-\eta\right)=0$ for all $t \geq t_{W}$. That is, when investors receive the warning at $t_{i}+\tau_{W}-\eta$, they deduce that they are type- $L$ investors. Conversely, $\mu_{t}\left(E \mid t_{i}, t_{W}=t_{i}+\tau_{W}\right)=1$ for all $t \geq t_{W}$. That is, when investors receive the warning at $t_{i}+\tau_{W}$, they deduce that they are type- $E$ investors. Next, suppose $\tau_{W} \in(0, \eta)$. The warning is issued after and before type- $E$ investors and type- $L$ investors, respectively receive a private signal. Then, $\mu_{t}\left(E \mid t_{i}, t_{W}<t_{i}\right)=0$ for all $t \geq t_{W}$. That is, when investors receive the warning before the private signal, they deduce that they are type- $L$ investors. On the other hand, when they receive the warning after the private signal, they deduce that they are type- $E$ investors: $\mu_{t}\left(E \mid t_{i}, t_{W}=t_{i}+\tau_{W}\right)=1$ for all $t \geq t_{W}$. Thus, all investors deduce their type via a public warning.

When the warning is issued, we can think of three strategies. Consider that all investors hold the assets until $t_{W}$. First, suppose investors choose $T\left(t_{i}, t_{W}\right)>T\left(t_{j}, t_{W}\right)$, where $i, j=E, L$ respectively. Then, a type- $i$ investor has an incentive to deviate by selling at $T\left(t_{j}, t_{W}\right)$, since his payoff increases from $\exp \left(g t_{0}\right)$ to $\exp \left(g T\left(t_{j}, t_{W}\right)\right)$. Thus, this is not an 
equilibrium strategy. Second, suppose investors choose $T\left(t_{i}, t_{W}\right)=T\left(t_{j}, t_{W}\right)>t_{W}$, where $i, j=E, L$ respectively. Then, a type- $i$ investor has an incentive to deviate by selling at $t \in\left[t_{W}, T\left(t_{j}, t_{W}\right)\right)$, since his payoff increases from $\exp \left(g t_{0}\right)$ to $\exp (g t)$. Thus, this is not an equilibrium strategy. Finally, suppose investors choose $T\left(t_{i}, t_{W}\right)=T\left(t_{j}, t_{W}\right)=t_{W}$, where $i, j=E, L$ respectively. All investors are indifferent between staying $t_{W}$ or deviating for any other period, since they would sell at a low price of $\exp \left(g t_{0}\right)$ regardless of the choice. Note that they cannot choose $T\left(t_{i}, t_{W}\right)<t_{W}$ at $t_{W}$. Thus, selling the asset at $t_{W}$ is an equilibrium strategy under the condition that the warning is issued.

However, selling the asset at (or after) $t_{W}$ cannot be an equilibrium strategy for the period before the warning is issued. Payoff from selling the asset at (or after) $t_{W}$ is $\exp \left(g t_{0}\right)$ regardless of investor type. If an investor deviates from the strategy and sells before the warning is issued, that is, at $t_{i}+\tau^{\prime}$ where $\tau^{\prime}<\tau_{W}$, he can sell the asset at a higher price of $\exp \left(g\left(t_{0}+\tau^{\prime}\right)\right)$, if he is type- $E$. Therefore, $T\left(t_{i}, t_{W}\right)=t_{i}+\tau$, where $\tau \geq \tau_{W}$ is not an equilibrium strategy. Instead, $T\left(t_{i}, t_{W}\right)=t_{i}+\tau$, where $\tau<\tau_{W}$, is an equilibrium strategy. Summing up, investors sell the assets before the warning is issued. Following Proposition 1 and the assumption $\tau_{W}<\tau^{*}$, the expected payoff decreases if an investor deviates from selling at $t_{i}+\tau$.

\section{A.3 Proof of Lemma 2}

Equation (4) can be derived in the following manner. If an investor is a type- $E$ investor, then $t_{i}$ equals $t_{0}$, and the probability that a public warning is issued at $t_{W}$ is

$$
f_{\frac{t_{i}}{\eta}}\left(\frac{t_{W}}{\eta}\right)=\frac{\exp \left(-\frac{t_{i}}{\eta}\right)\left(\frac{t_{i}}{\eta}\right)^{\frac{t_{W}}{\eta}}}{\left(\frac{t_{W}}{\eta}\right) !} .
$$

If the investor is a type- $L$ investor, then $t_{i}$ equals $t_{0}+\eta$, and the probability that a public warning is issued at $t_{W}=t_{i}$ is

$$
f_{\frac{t_{i}-\eta}{\eta}}\left(\frac{t_{W}}{\eta}\right)=\frac{\exp \left(-\frac{t_{i}-\eta}{\eta}\right)\left(\frac{t_{i}-\eta}{\eta}\right)^{\frac{t_{W}}{\eta}}}{\left(\frac{t_{W}}{\eta}\right) !} .
$$


Thus, the posterior belief that the investor is a type- $E$ investor after receiving the warning at $t_{W}$ is

$$
\mu_{t}\left(E \mid t_{i}, t_{W}\right)=\frac{f_{\frac{t_{i}}{\eta}}\left(\frac{t_{W}}{\eta}\right) \alpha}{f_{\frac{t_{i}}{\eta}}\left(\frac{t_{W}}{\eta}\right) \alpha+f_{\frac{t_{i}-\eta}{\eta}}\left(\frac{t_{W}}{\eta}\right)(1-\alpha)}=\left(1+\frac{1-\alpha}{\alpha} h\left(t_{i}, t_{W}\right)\right)^{-1}
$$

for all $t \geq \max \left\{t_{i}, t_{W}\right\}$. Here, we define $h\left(t_{i}, t_{W}\right)$ by

$$
h\left(t_{i}, t_{W}\right)=\frac{f_{t_{i}-\eta}\left(\frac{t_{W}}{\eta}\right)}{f_{\frac{t_{i}}{\eta}}\left(\frac{t_{W}}{\eta}\right)}=\frac{\frac{\exp \left(-\frac{t_{i}-\eta}{\eta}\right)\left(\frac{t_{i}-\eta}{\eta}\right)^{\frac{t_{W}}{\eta}}}{\left(\frac{t_{W}}{\eta}\right) !}}{\frac{\exp \left(-\frac{t_{i}}{\eta}\right)\left(\frac{t_{i}}{\eta}\right)^{\frac{t_{W}}{\eta}}}{\left(\frac{t_{W}}{\eta}\right) !}}=\exp (1)\left(1-\frac{\eta}{t_{i}}\right)^{\frac{t_{W}}{\eta}}
$$

We examine the properties of $h\left(t_{i}, t_{W}\right)$ and $\mu_{t}\left(E \mid t_{i}, t_{W}\right)$. First, it is clear that $h\left(t_{i}, t_{W}\right)$ decreases with $t_{W}$, and hence, $\mu_{t}\left(E \mid t_{i}, t_{W}\right)$ increases with $t_{W}$. This implies that investors believe that they are more likely to be type- $E$ (type- $L$ ) as the public warning is issued later (earlier).

Second, it is also clear that $h\left(t_{i}, t_{W}\right)$ increases with $t_{i}$, and hence, $\mu_{t}\left(E \mid t_{i}, t_{W}\right)$ decreases with $t_{i}$. This implies that investors believe that they are more likely to be type- $L$ (type- $E$ ) as the private signal is received later (earlier).

Next, we show that if $t_{W} \geq t_{i}(>0), \mu_{t}\left(E \mid t_{i}, t_{W}\right)>\alpha$. Note $\lim _{x \rightarrow \infty}(1-1 / x)^{x}=$ $\exp (1)^{-1}$. The value of $(1-1 / x)^{x}$ increases with $x$ when $x \geq 1$, which means $\exp (1)(1-1 / x)^{x}<$ 1 for all $x \geq 1$. As a result, $h\left(t_{i}, t_{W}\right)=\exp (1)\left(1-\eta / t_{i}\right)^{t_{W} / \eta}$ is less than 1 when $t_{W}=t_{i}$. Because $h\left(t_{i}, t_{W}\right)$ decreases with $t_{W}, h\left(t_{i}, t_{W}\right)=\exp (1)\left(1-\left(t_{i} / \eta\right)^{-1}\right)^{t_{W} / \eta}$ is less than 1 and $\mu_{t}\left(E \mid t_{i}, t_{W}\right)$ is more than $\alpha$ for all $t_{W} \geq t_{i}(>0)$.

Finally, we show that if $t_{W} \leq t_{i}-\eta, \mu_{t}\left(E \mid t_{i}, t_{W}\right)<\alpha$. Note $\lim _{x \rightarrow \infty}(1-1 / x)^{x-1}=$ $\exp (1)^{-1}$ and $\lim _{x \rightarrow 1}(1-1 / x)^{x-1}=1$. The value of $(1-1 / x)^{x-1}$ decreases with $x$ when $x \geq 1$, which means $\exp (1)(1-1 / x)^{x-1}>1$ for all $x \geq 1$. As a result, $h\left(t_{i}, t_{W}\right)=$ $\exp (1)\left(1-\eta / t_{i}\right)^{t_{W} / \eta}$ is more than 1 when $t_{W}=t_{i}-\eta$. Because $h\left(t_{i}, t_{W}\right)$ decreases with $t_{W}, h\left(t_{i}, t_{W}\right)=\exp (1)\left(1-\left(t_{i} / \eta\right)^{-1}\right)^{t_{W} / \eta}$ is more than 1 and $\mu_{t}\left(E \mid t_{i}, t_{W}\right)$ is less than $\alpha$ for all $t_{W} \leq t_{i}-\eta$. 


\section{A.4 Proof of Proposition 3}

Suppose that investors choose to sell the asset at $T\left(t_{i}, t_{W}\right)=t_{i}+\tau\left(t_{i}, t_{W}\right)$. Then, the expected payoff is

$$
\mu_{t}\left(E \mid t_{i}, t_{W}\right) \exp \left(g\left(t_{i}+\tau\left(t_{i}, t_{W}\right)\right)\right)+\left(1-\mu_{t}\left(E \mid t_{i}, t_{W}\right)\right) \exp \left(g\left(t_{i}-\eta\right)\right) .
$$

The first term depicts a payoff for a type- $E$ investor, and the second, for a type- $L$ investor.

There are three possible deviations from $t_{i}+\tau\left(t_{i}, t_{W}\right)$ : selling the asset at $t_{i}+\tau$, where (i) $\tau>\tau\left(t_{i}, t_{W}\right)$, (ii) $\tau\left(t_{i}-\eta, t_{W}\right)<\tau<\tau\left(t_{i}, t_{W}\right)$, or (iii) $\tau \leq \tau\left(t_{i}-\eta, t_{W}\right)$.

(i) Deviate to $t_{i}+\tau$, where $\tau>\tau\left(t_{i}, t_{W}\right)$ : By $t_{0}+\tau\left(t_{i}, t_{W}\right)$, the bubble certainly bursts, so his expected payoff decreases to $\exp \left(g\left(t_{0}\right)\right)$ due to this deviation.

(ii) Deviate to $t_{i}+\tau$, where $\tau\left(t_{i}-\eta, t_{W}\right)<\tau<\tau\left(t_{i}, t_{W}\right)$ : If he is a type- $L$ investor, his payoff does not change by this deviation. If he is a type- $E$ investor, his payoff decreases because $\exp \left(g\left(t_{i}+\tau\right)\right)<\exp \left(g\left(t_{i}+\tau\left(t_{i}, t_{W}\right)\right)\right)$. Therefore, his expected payoff decreases by this deviation.

(iii) Deviate to $t_{i}+\tau$, where $\tau \leq \tau\left(t_{i}-\eta, t_{W}\right)$ : By this deviation, he surely succeeds in selling his asset before the bubble bursts. The expected payoff from this deviation is maximized when they deviate to sell at $\tau\left(t_{i}-\eta, t_{W}\right)$; thus, the highest expected payoff from this deviation is $\exp \left(g\left(t_{i}+\tau\left(t_{i}-\eta, t_{W}\right)\right)\right)$. The type- $t_{i}$ investor does not deviate from $T\left(t_{i}, t_{W}\right)=t_{i}+\tau\left(t_{i}, t_{W}\right)$ in this way on the following condition:

$$
\begin{aligned}
& \mu_{t}\left(E \mid t_{i}, t_{W}\right) \exp \left(g\left(t_{i}+\tau\left(t_{i}, t_{W}\right)\right)\right)+\left(1-\mu_{t}\left(E \mid t_{i}, t_{W}\right)\right) \exp \left(g\left(t_{i}-\eta\right)\right) \\
\geq & \exp \left(g\left(t_{i}-\eta+\tau\left(t_{i}-\eta, t_{W}\right)\right)\right)
\end{aligned}
$$

This condition is equivalent to (5).

If the condition (5) is satisfied for all possible timings of $t_{i}$, where $t_{i} \in[2 \eta, \infty)$, it constitutes an equilibrium. If $t_{i}=\eta$, this investor can deduce his type as type- $E$. Indeed, $\mu_{t}\left(E \mid t_{i}=\eta, t_{W}\right)=1$ for all $t_{W}$. The investor sells his asset before type- $L$ investors who receive the private signal at $2 \eta$ sell their assets. Thus, the inequality $\tau\left(\eta, t_{W}\right) \leq \tau\left(2 \eta, t_{W}\right)+\eta$ must be satisfied. 
Suppose that a type- $t_{i}$ investor is type- $E$. From the perspective of the type- $t_{i}$ investor, the other type- $L$ investors are type- $\left(t_{i}+\eta\right)$. Because $\mu_{t}\left(E \mid t_{i}, t_{W}\right)$ decreases with $t_{i}$ due to Lemma 2 , the type- $t_{i}$ investor may hold the asset too long such that he cannot sell before the type- $\left(t_{i}+\eta\right)$ investor $\left(\tau\left(t_{i}, t_{W}\right) \geq \tau\left(t_{i}+\eta, t_{W}\right)+\eta\right)$. Note that if $\tau\left(t_{i}, t_{W}\right) \geq \tau\left(t_{i}+\eta, t_{W}\right)+\eta$, the right-hand side of $(7)$ is always greater than the left-hand side, except for the case of $\mu_{t}\left(E \mid t_{i}, t_{W}\right)=1$. Thus, if $(5)((7))$ is satisfied, the inequality $\tau\left(t_{i}, t_{W}\right)<\tau\left(t_{i}+\eta, t_{W}\right)+\eta$, is also satisfied. Therefore, the type- $t_{i}$ investor sells before the type- $\left(t_{i}+\eta\right)$ investor, unless $\mu_{t}\left(E \mid t_{i}, t_{W}\right)=1$.

Note that if $t_{W}=0$, investors' revised beliefs become $\mu_{t}\left(E \mid t_{i}, t_{W}=0\right)=(1+\exp (1)(1-\alpha) / \alpha)^{-1}$, which does not depend on $t_{i}$. All investors have the same beliefs; the symmetric equilibrium strategy is written as $T\left(t_{i}\right)=t_{i}+\tau$ for all $i$.

\section{B Coalition-proof Nash equilibrium}

\section{B.1 Minor Changes in Settings}

First, we make minor changes in our settings in order to apply a coalition-proof Nash equilibrium. Instead of assuming continuous investors of size one, suppose that there are finite $N \geq 5$ investors, and $\bar{\alpha} N$ of them are type- $E$ investors, where $\bar{\alpha} N$ is a positive integer. Suppose also that if $\bar{\alpha} N-1$ or more investors sell their assets before the other investors, the bubble bursts endogenously. In other words, even though one investor deviates by selling later, the bubble bursts if all other type- $E$ investors sell the assets.

Wherever possible, we also need to assume that the beliefs are consistent with Bayes' Rule, since a coalition-proof Nash equilibrium does not have any restriction on players' beliefs. $^{21}$

\footnotetext{
${ }^{21}$ Moreno and Wooders (1996) showed a coalition-proof equilibrium with incomplete information and a correlated strategy.
} 


\section{B.2 Corollary}

With these minor changes, we show that the existence and uniqueness of the pure-strategy and symmetric coalition-proof Nash equilibrium is the same as that in Abreu and Brunnermeier (2003).

Corollary 1 According to the pure-strategy and symmetric coalition-proof Nash equilibrium with consistent beliefs in our model, all investors sell at $t_{i}+\tau^{*}$. In equilibrium outcomes, the bubble bursts at $t_{0}+\tau^{*}$. This equilibrium is unique.

Proof: Existence: Suppose that all investors choose $t_{i}+\tau$. According to the proof of Proposition 1, the investor has an incentive to deviate from $t_{i}+\tau$ if $\tau>\tau^{*}$; he does not deviate if $\tau \leq \tau^{*}$.

In a coalition-proof Nash equilibrium, all investors sell their assets at $t_{i}+\tau^{*}$. Suppose that all investors sell the asset at $t_{i}+\tau^{*}$. From this state, suppose that all (or some) investors make a (sub)coalition and deviate by selling later than $t_{i}+\tau^{*}$. Further suppose that, by this deviation, all investors' payoffs can be improved because they can sell with a higher price if they are type- $E$ investors, and the payoff does not change if they are type- $L$ investors. ${ }^{22}$ However, an investor has an incentive to deviate from this deviation by selling earlier, and hence, this deviation is not self-enforcing. Suppose that all (or some) investors make a (sub)coalition and deviate by selling earlier than $t_{i}+\tau^{*}$. By this deviation, these investors' payoffs decrease. Thus, there is no profitable self-enforcing deviation, and hence, this constitutes a coalition-proof Nash equilibrium.

Uniqueness: In the unique pure-strategy and symmetric coalition-proof Nash equilibrium, all investors sell their asset at $t_{i}+\tau^{*}$. Suppose that all investors sell their asset at $t_{i}+\tau^{\prime}$, where $\tau^{\prime}<\tau^{*}$. Then, if all investors make a coalition and deviate by selling at $t_{i}+\tau^{*}$, their payoffs can be improved because they can sell at a higher price if they are type- $E$ investors, and the payoff does not change if they are type- $L$ investors. Moreover, no one (and no subcoalition) has an incentive to deviate from this deviation, because no one (and no subcoalition) has an incentive to sell earlier. In addition, it is not a self-enforcing deviation that all (some)

\footnotetext{
${ }^{22}$ Depending on the members of a subcoalition, the period when the bubble crashes may not change even if these members deviate at the same time. In this case, the deviation cannot be profitable.
} 
investors make a (sub)coalition and deviate by selling later than $t_{i}+\tau^{*}$, owing to the same reason as in the previous case. Thus, this deviation is self-enforcing, and selling at $t_{i}+\tau^{\prime}$, where $\tau^{\prime}<\tau^{*}$, is not a coalition-proof Nash equilibrium. Moreover, all investors selling their assets at $t_{i}+\tau^{\prime}$, where $\tau^{\prime}>\tau^{*}$, does not constitute a coalition-proof Nash equilibrium, since an investor has an incentive to deviate to sell earlier. Thus, selling at $t_{i}+\tau^{*}$ constitutes the unique pure-strategy and symmetric coalition-proof Nash equilibrium.

\section{Two-Period Warning}

\section{C.1 Equilibrium}

In this appendix, we consider another type of definite-range warning, namely, a two-period warning. It is issued in one of two definite periods around the starting period of the bubble. Specifically, we suppose that a warning is issued after the bubble starts. The date of the warning $\left(t_{W}=t_{0}+\tau_{W}\right)$ is distributed over several periods after the bubble starts. Suppose that the warning period $\left(t_{W}\right)$ is $t_{0}+2 \eta$ with probability $p \in(0,1)$ and $t_{0}+3 \eta$ with probability $1-p$. Assume that $3 \eta \leq \tau^{*}{ }^{23}$ This timing is shown in Figure 3 .

[Figure 3 Here]

Even with a two-period warning, the bubble bursts immediately when a warning is issued, and the bubble may burst before a warning is issued. To be precise, the following proposition is obtained.

Proposition 4 Suppose that a public warning is issued in period $t_{0}+2 \eta$ with probability $p$ and in period $t_{0}+3 \eta$ with probability $1-p$, where $3 \eta<\tau^{*}$. Then, there exists an equilibrium with the following properties.

1. If a warning is issued at $t_{i}+\eta$ or $t_{i}+2 \eta$, investors sell the asset immediately $\left(T\left(t_{i}, t_{W}=\right.\right.$ $\left.\left.t_{i}+2 \eta\right)=T\left(t_{i}, t_{W}=t_{i}+\eta\right)=t_{W}\right)$. The beliefs are $\mu_{t}\left(E \mid t_{i}, t_{W}=t_{i}+\eta\right)=0$ for all $t \geq t_{W}=t_{i}+\eta$ and $\mu_{t}\left(E \mid t_{i}, t_{W}=t_{i}+2 \eta\right)=1$ for all $t \geq t_{W}=t_{i}+2 \eta$.

\footnotetext{
${ }^{23}$ Note that if $\tau^{*} \leq 2 \eta$, both warnings are meaningless, because they are issued after the bubble crashes endogenously. Suppose $2 \eta<\tau^{*}<3 \eta$, and this situation becomes similar to that of the deterministic warning.
} 
2. If a warning is not issued at $t_{i}+\eta$, the beliefs are $\mu_{t}\left(E \mid t_{i}, t_{W}>t_{i}+\eta\right)=\alpha /(\alpha+(1-\alpha) p) \alpha$ for all $t \in\left[t_{i}+\eta, t_{i}+2 \eta\right)$. If a warning is issued neither at $t_{i}+\eta$ nor at $t_{i}+2 \eta$, the beliefs are $\mu_{t}\left(E \mid t_{i}, t_{W}>t_{i}+2 \eta\right)=1$ for all $t \geq t_{i}+2 \eta$.

3. Investors sell the asset at $T\left(t_{i}, t_{W}\right)=t_{i}+\tau$, where $0 \leq \tau \leq 2 \eta$ for all $p$.

4. If and only if

$$
p \leq \frac{\exp \left(g \tau^{* *}\right)-\exp (2 g \eta)}{\exp \left(g \tau^{* *}\right)-1}
$$

investors sell the asset at $T\left(t_{i}, t_{W}\right)=t_{i}+\tau$ where $\tau$ satisfies $\tau \in\left[\tau_{1}, \tau_{2}\right]$ and $\tau<3 \eta$. The values of $\tau_{1}, \tau_{2}$, and $\tau^{* *}$ are defined by

$$
\begin{gathered}
p=\frac{\exp \left(g \tau_{1}\right)-\exp (2 g \eta)}{\exp \left(g \tau_{1}\right)-1} \\
p=\frac{\exp \left(g \tau_{2}\right)-\exp \left(g\left(\tau_{2}-\eta\right)\right)}{\exp \left(g \tau_{2}\right)-1} \frac{\alpha}{\alpha+(1-\alpha) \exp (-g \eta)}, \text { and } \\
\exp \left(g \tau^{* *}\right)=\alpha \exp (3 g \eta)+(1-\alpha) \exp (2 g \eta) .
\end{gathered}
$$

Proof: See the next subsection.

The intuition is as follows. With a two-period warning, type- $E$ investors receive the warning at either $t_{i}+2 \eta$ or $t_{i}+3 \eta$. Type- $L$ investors receive the warning at either $t_{i}+\eta$ or $t_{i}+2 \eta$. Thus, type- $L$ investors who receive the warning at $t_{i}+\eta$ can deduce their type (when the warning is issued at $\left.t_{0}+2 \eta\right)$. Type- $E$ investors who receive it at $t_{i}+3 \eta$ can deduce their type (when the warning is not issued at $t_{0}+2 \eta$ ). This means that investors who receive the warning at $t_{i}+2 \eta$ believe that their type has been deduced by the other investor type, and thus, they have no hope of selling their assets at a higher price after the warning is issued. Therefore, an investor who receives the warning at $t_{i}+2 \eta$ sells his asset immediately, and the bubble bursts. Anticipating this event, investors who receive the warning at $t_{i}+\eta$ also sell their asset immediately, implying that if the warning is issued, the bubble bursts immediately. ${ }^{24}$ Therefore, no investor has an incentive to hold the asset after $t_{i}+3 \eta$ since the bubble will continue at most till $t_{0}+3 \eta$.

\footnotetext{
${ }^{24} \mathrm{~A}$ (type- $E$ ) investor who does not receive the warning at either $t_{i}+\eta$ or $t_{i}+2 \eta$ sells his asset before $t_{i}+3 \eta$, that is, before the type- $L$ investor receives the warning.
} 
Consider a situation in which a warning is not yet issued. If the probability of being a type- $E$ investor $(\alpha)$ is low, and the probability that a warning is issued at $t_{0}+2 \eta(p)$ is high (i.e., (8) does not hold), investors are highly apprehensive in that they cannot sell the assets at a higher price. Thus, they do not hold the assets longer than $t_{i}+2 \eta$. Otherwise (i.e., if (8) holds), they have an incentive to hold the assets and sell after $t_{i}+2 \eta$. In the latter case, a warning may be issued at $t_{i}+2 \eta$, and the bubble bursts with this warning. In the other case, type- $E$ investors hold the assets after $t_{i}+2 \eta$ and sell before the warning is issued. The warning is thus not issued in equilibrium outcomes. ${ }^{25}$

\section{C.2 Proof of Proposition 4}

\section{C.2.1 Equilibrium strategy at $t \geq t_{W}$}

We examine the equilibrium strategies of investors under the condition that a warning is issued, that is, $t \geq t_{W}$. Note that type- $E$ investors receive the warning at either $t_{E}+2 \eta$ or $t_{E}+3 \eta$. Type- $L$ investors receive the warning at either $t_{L}+\eta$ or $t_{L}+2 \eta$. That is, the public warning may be received at three possible timings: $t_{i}+\eta, t_{i}+2 \eta$, and $t_{i}+3 \eta$.

1. Strategies of investors who receive the warning at $t_{i}+\eta$ : The belief of these investors is $\mu_{t}\left(E \mid t_{i}, t_{W}=t_{i}+\eta\right)=0$ for all $t \geq t_{i}+\eta$. That is, if investors receive the warning at $t_{i}+\eta$, they can deduce that they are type- $L$ investors. They also deduce that the other investors are type- $E$ investors, who have received the warning at $t_{i}+2 \eta$. Such type- $L$ investors do not choose the strategy $T\left(t_{L}, t_{W}=t_{L}+\eta\right) \geq T\left(t_{E}, t_{W}=t_{E}+2 \eta\right)>t_{W}$. A type- $L$ investor can increase his payoff from $\exp \left(g t_{0}\right)$ to $\exp (g t)$ by selling the asset before the type- $E$ investor sells, that is, at $t \in\left[t_{W}, T\left(t_{E}, t_{W}=t_{E}+2 \eta\right)\right)$. Such type- $L$ investors do not choose the strategy $T\left(t_{L}, t_{W}=t_{L}+\eta\right)>T\left(t_{E}, t_{W}=t_{E}+2 \eta\right)=t_{W}$ either. A type- $L$ investor can increase his payoff from $\exp \left(g t_{0}\right)$ to $\exp \left(g t_{W}\right)$ by selling the asset at $t_{W}$.

2. Strategies of investors who receive the warning at $t_{i}+3 \eta$ : The belief of these investors

\footnotetext{
${ }^{25}$ If a warning is issued before the bubble starts (e.g., the warning period $\left(t_{W}\right)$ is $t_{0}-\eta$ with probability $p$ and is $t_{0}-2 \eta$ with probability $1-p$ ), the bubble crashes before type- $L$ investors receive the private signal. This suggests that the bubble does not occur, or that even if it does, it bursts soon.
} 
is $\mu_{t}\left(E \mid t_{i}, t_{W}=t_{i}+3 \eta\right)=1$ for all $t \geq t_{i}+3 \eta$. That is, if investors receive the warning at $t_{i}+3 \eta$, they deduce that they are type- $E$ investors. Moreover, they deduce that the other type of investors are type- $L$ investors, who have received the warning at $t_{i}+2 \eta$. Such type- $E$ investors do not choose the strategy $T\left(t_{E}, t_{W}=t_{E}+3 \eta\right) \geq$ $T\left(t_{L}, t_{W}=t_{L}+2 \eta\right)>t_{W}$. A type- $E$ investor can increase his payoff from $\exp \left(g t_{0}\right)$ to $\exp (g t)$ by selling the asset before the type- $L$ investor, that is, at $t \in\left(t_{i}, T\left(t_{L}, t_{W}=\right.\right.$ $\left.\left.t_{L}+2 \eta\right)\right)$. Note that such type- $E$ investors can deduce their type not at $t_{i}+3 \eta$ but at $t_{i}+2 \eta$, because type- $L$ investors should receive the warning by $t_{i}+2 \eta$. In other words, they deduce their type before the warning is issued; their belief is written as $\mu_{t}\left(E \mid t_{i}, t_{W} \geq t_{i}+2 \eta\right)=1$ for all $t \geq t_{i}+2 \eta$. Moreover, they do not choose the strategy $T\left(t_{E}, t_{W}>t_{E}+2 \eta\right) \geq T\left(t_{L}, t_{W}=t_{L}+2 \eta\right)=t_{W}$. Alternatively, such investors choose to sell at $t<t_{W}=t_{0}+3 \eta$ since his payoff increases from $\exp \left(g t_{0}\right)$ to $\exp (g t)$.

3. Strategies of investors who receive the warning at $t_{i}+2 \eta$ : Such investors do not choose the strategy $T\left(t_{i}, t_{W}=t_{i}+2 \eta\right) \geq \max \left\{T\left(t_{E}, t_{W}>t_{E}+2 \eta\right), T\left(t_{L}, t_{W}=t_{L}+\eta\right)\right\}>$ $t_{W}$. An investor has an incentive to deviate by selling at $t<\max \left\{T\left(t_{E}, t_{W}>t_{E}+\right.\right.$ $\left.2 \eta), T\left(t_{L}, t_{W}=t_{L}+\eta\right)\right\}$, because his payoff increases from $\exp \left(g t_{0}\right)$ to $\exp (g t)$ with a positive probability. Such investors also do not choose the strategy $T\left(t_{i}, t_{W}=t_{i}+2 \eta\right)>$ $\max \left\{T\left(t_{E}, t_{W}>t_{E}+2 \eta\right), T\left(t_{L}, t_{W}=t_{L}+\eta\right)\right\}=t_{W}$. An investor can increase his payoff from $\exp \left(g t_{0}\right)$ to $\exp \left(g t_{W}\right)$ with a positive probability by selling the asset at $t_{W}$.

Combining three cases, we see that the equilibrium strategies are given by $T\left(t_{i}, t_{W}=\right.$ $\left.t_{i}+2 \eta\right)=T\left(t_{i}, t_{W}=t_{i}+\eta\right)=t_{W}$ and $T\left(t_{i}, t_{W}>t_{i}+2 \eta\right)<t_{i}+3 \eta$. With these strategies, if an investor receives the warning at $t_{i}+\eta$ or $t_{i}+2 \eta$, his payoff is $\exp \left(g\left(t_{0}\right)\right)$. At $t_{W}$, no one has an incentive to deviate from $T\left(t_{i}, t_{W}=t_{i}+2 \eta\right)=T\left(t_{i}, t_{W}=t_{i}+\eta\right)=t_{W}$, since the payoff is $\exp \left(g\left(t_{0}\right)\right)$ regardless of deviation. If an investor does not receive the warning until $t_{i}+2 \eta$, he deduces his type as being type- $E$ and sells the asset before $t_{W}=t_{0}+3 \eta$. Denoting the time to sell by at $t_{i}+\tau$, where $\tau<3 \eta$, his payoff is $\exp \left(g\left(t_{i}+\tau\right)\right)$. Such an investor does not have an incentive to sell later than $t_{i}+\tau$, because the bubble bursts at $t_{i}+\tau$, and his payoff decreases to $\exp \left(g\left(t_{0}\right)\right)$. He does not have an incentive to sell earlier than $t_{i}+\tau$ either, because the asset price increases to $\exp \left(g\left(t_{i}+\tau\right)\right)$ if he waits until $t_{i}+\tau$. 
Note that because of these equilibrium strategies, type- $L$ investors never receive a warning at $t_{i}+2 \eta$; therefore, $\mu_{t}\left(E \mid t_{i}, t_{W}=t_{i}+2 \eta\right)=1$ constitutes an equilibrium.

\section{C.2.2 Equilibrium strategy at $t<t_{W}$}

Next, we examine the equilibrium strategies of investors before a warning is issued, that is, at $t<t_{W}$. As for $t$, three cases need to be considered: $t<t_{i}+\eta, t_{i}+\eta \leq t<t_{i}+2 \eta$, and $t \geq t_{i}+2 \eta$. First, consider $t<t_{i}+\eta$. Due to Proposition 1, this constitutes an equilibrium. Second, for $t \geq t_{i}+2 \eta$, if an investor does not receive a warning at $t_{i}+2 \eta$, he can deduce his type (type- $E$ ), that is, $\mu_{t}\left(E \mid t_{i}, t_{W}>t_{i}+2 \eta\right)=1$. His equilibrium strategy is $T\left(t_{i}, t_{W}>t_{i}+2 \eta\right)<t_{i}+3 \eta$ after $t_{i}+2 \eta$, as stated above.

Regarding $t_{i}+\eta \leq t<t_{i}+2 \eta$, there are two possible equilibrium strategies: selling the asset at $t_{i}+\tau$, where (i) $\tau<2 \eta$ (selling before a possible warning at $t_{0}+2 \eta$ ) or (ii) $2 \eta \leq \tau<3 \eta$ (selling after a possible warning at $t_{0}+2 \eta$ ). Strategy (i) constitutes an equilibrium. Deviating to sell in both an earlier and a later period decreases the investor's payoff.

We examine whether strategy (ii), namely selling the asset after $t_{i}+2 \eta$, can denote another equilibrium. At $t_{i}+\eta$, when no warning is issued, the belief about being a type- $E$ investor is revised from $\alpha$. The probability that investors do not receive a warning at $t_{i}+\eta$ is given by $\alpha+(1-\alpha) p$. The first term corresponds to the case in which they are type- $E$ investors. The second term corresponds to the case in which they are type- $L$ investors, and the warning was not issued at $t_{L}+\eta=t_{0}+2 \eta$. Therefore, we obtain the revised belief as

$$
\mu_{t}\left(E \mid t_{i}, t_{W}>t_{i}+\eta\right)=\frac{\alpha}{\alpha+(1-\alpha) p} .
$$

From strategy (ii), the investor expects the payoff

$$
\begin{gathered}
\mu_{t}\left(E \mid t_{i}, t_{W}>t_{i}+\eta\right)(1-p) \exp \left(g\left(t_{i}+\tau\right)\right)+\mu_{t}\left(E \mid t_{i}, t_{W}>t_{i}+\eta\right) p \exp \left(g\left(t_{i}\right)\right) \\
+\left(1-\mu_{t}\left(E \mid t_{i}, t_{W}>t_{i}+\eta\right)\right) \exp \left(g\left(t_{i}-\eta\right)\right)
\end{gathered}
$$

under the condition that he is at $t_{i}+\eta$ and has not received a warning till then. If he is a type- $E$ investor, the probability that the warning is issued at $t_{i}+2 \eta$ is $p$. The first term of (9) suggests that with $\mu_{t}\left(E \mid t_{i}, t_{W}>t_{i}+\eta\right)(1-p)$, the investor is a type- $E$ investor, and the public 
warning is not issued at $t_{i}+2 \eta$. Such an investor can succeed in selling at $t_{i}+\tau$ and receive $\exp \left(g\left(t_{i}+\tau\right)\right)$, where $2 \eta \leq \tau<3 \eta$. The second term suggests that with $\mu_{t}\left(E \mid t_{i}, t_{W}>t_{i}+\eta\right) p$, the investor is a type- $E$ investor, and the public warning is issued at $t_{i}+2 \eta$. The bubble bursts immediately after the warning, and the asset price falls to $\exp \left(g\left(t_{0}\right)\right)$. The investor receives $\exp \left(g\left(t_{i}\right)\right)$. The third term suggests that with $1-\mu_{t}\left(E \mid t_{i}, t_{W}>t_{i}+\eta\right)$, the investor is a type- $L$ investor. Such an investor cannot sell at the high price, and hence, he receives only $\exp \left(g\left(t_{i}-\eta\right)\right)$, because $t_{0}=t_{L}-\eta$.

There are four possible deviations from selling the asset at $t_{i}+\tau$, where $2 \eta \leq \tau<3 \eta$ to selling it at $t_{i}+\tau^{\prime}$, where (i) $\tau^{\prime}>\tau$, (ii) $2 \eta \leq \tau^{\prime}<\tau$, (iii) $\tau-\eta<\tau^{\prime}<2 \eta$, and (iv) $\tau^{\prime} \leq \tau-\eta$

(i) If the investor deviates to selling the asset at $t_{i}+\tau^{\prime}$, where $\tau^{\prime}>\tau$ : Even though he deviates and sells later, the bubble certainly bursts by $t_{i}+\tau$, because he is a pricetaker. His expected payoff decreases to $\exp \left(g\left(t_{0}\right)\right)$ by this deviation.

(ii) If the investor deviates to selling the asset at $t_{i}+\tau^{\prime}$, where $2 \eta \leq \tau^{\prime}<\tau$ : By this deviation, his expected payoff becomes

$$
\begin{aligned}
\mu_{t}\left(E \mid t_{i}, t_{W}>t_{i}+\eta\right)(1-p) \exp \left(g\left(t_{i}+\tau^{\prime}\right)\right)+\mu_{t}\left(E \mid t_{i}, t_{W}>t_{i}+\eta\right) p \exp \left(g\left(t_{i}\right)\right) \\
+\left(1-\mu_{t}\left(E \mid t_{i}, t_{W}>t_{i}+\eta\right)\right) \exp \left(g\left(t_{i}-\eta\right)\right) .
\end{aligned}
$$

Clearly, this is lower than (9). Thus, his expected payoff declines.

(iii) If the investor deviates to selling the asset at $t_{i}+\tau^{\prime}$, where $\tau-\eta<\tau^{\prime}<2 \eta$ : If the investor is a type- $L$ investor, he still cannot sell before or at the same time as a type- $E$ investor. However, if he is a type- $E$ investor, he can sell the asset before a possible warning at $t_{0}+2 \eta$. Thus, his expected payoff becomes

$$
\mu_{t}\left(E \mid t_{i}, t_{W}>t_{i}+\eta\right) \exp \left(g\left(t_{i}+\tau^{\prime}\right)\right)+\left(1-\mu_{t}\left(E \mid t_{i}, t_{W}>t_{i}+\eta\right)\right) \exp \left(g\left(t_{i}-\eta\right)\right)
$$

Clearly, as $\tau^{\prime}$ is closer to $2 \eta$, his expected payoff increases to

$$
\mu_{t}\left(E \mid t_{i}, t_{W}>t_{i}+\eta\right) \exp \left(g\left(t_{i}+2 \eta\right)\right)+\left(1-\mu_{t}\left(E \mid t_{i}, t_{W}>t_{i}+\eta\right)\right) \exp \left(g\left(t_{i}-\eta\right)\right) .
$$


No investor has an incentive to deviate in this way if the payoff is not higher than (9), that is,

$$
p \leq F(\tau) \equiv \frac{\exp (g \tau)-\exp (2 g \eta)}{\exp (g \tau)-1} .
$$

Note that $F(\tau)$ increases with $\tau$.

(iv) If the investor deviates to selling the asset at $t_{i}+\tau^{\prime}$, where $\tau^{\prime} \leq \tau-\eta$ : By this deviation, he succeeds in selling his asset before the bubble bursts. The expected payoff from this deviation is maximized when he deviates to sell at $t_{i}+\tau-\eta$, and the highest expected payoff from this deviation becomes $\exp \left(g\left(t_{i}+\tau-\eta\right)\right)$. Such a deviation is worse off if the payoff is not higher than (9), that is,

$$
p \leq G(\tau) \equiv \frac{\exp (g \tau)-\exp (g(\tau-\eta))}{\exp (g \tau)-1} \frac{\alpha}{\alpha+(1-\alpha) \exp (-g \eta)}
$$

Note that $G(\tau)$ decreases with $\tau$.

Summing up (i) to (iv) reveals that (10) and (11) are the two necessary conditions for the existence of the strategy wherein the investor sells the asset at $t_{i}+\tau$, where $2 \eta \leq \tau<3 \eta$.

Now, suppose that period $t_{i}+\eta$ has passed $\left(t \geq t_{i}+\eta\right)$, but a warning is not issued. Then, the belief is $\mu_{t}\left(E \mid t_{i}, t_{W}>t_{i}+\eta\right)=\frac{\alpha}{\alpha+(1-\alpha) p}$. One of the investors' strategies is to sell the asset at $T\left(t_{i}, t_{W}>t_{i}+\eta\right)=t_{i}+\tau$, where $\tau$ satisfies $2 \eta \leq \tau<3 \eta$, (10), and (11). We define $\tau_{1}$ and $\tau_{2}$, which equalize (10) and (11), respectively:

$$
\begin{gathered}
p=F\left(\tau_{1}\right)=\frac{\exp \left(g \tau_{1}\right)-\exp (2 g \eta)}{\exp \left(g \tau_{1}\right)-1} . \\
p=G\left(\tau_{2}\right)=\frac{\exp \left(g \tau_{2}\right)-\exp \left(g\left(\tau_{2}-\eta\right)\right)}{\exp \left(g \tau_{2}\right)-1} \frac{\alpha}{\alpha+(1-\alpha) \exp (-g \eta)} .
\end{gathered}
$$

Then, equilibrium $\tau$ needs to satisfy $\tau_{1} \leq \tau \leq \tau_{2}$ and $2 \eta \leq \tau<3 \eta$, because $F(\tau)$ and $G(\tau)$ are increasing and decreasing with $\tau$, respectively.

If $p$ is sufficiently low, there exists $\tau$ that satisfies $\tau_{1} \leq \tau \leq \tau_{2}$ and $2 \eta \leq \tau<3 \eta$. This is because $F(\tau)$ and $G(\tau)$ are strictly positive for $2 \eta<\tau<3 \eta$. Note that $2 \eta<\tau_{1}$ since $p$ is positive.

To be precise, the following lemma provides the value of $p$ such that $\tau$ satisfies $\tau_{1} \leq \tau \leq \tau_{2}$ and $2 \eta \leq \tau<3 \eta$. We define $\tau^{* *} \in(2 \eta, 3 \eta)$ that equalizes $F(\tau)$ with $G(\tau)$, that is,

$$
\exp \left(g \tau^{* *}\right)=\alpha \exp (3 g \eta)+(1-\alpha) \exp (2 g \eta)
$$


Lemma 3 There exists $\tau$ that satisfies $\tau_{1} \leq \tau \leq \tau_{2}$ and $2 \eta \leq \tau<3 \eta$ if and only if

$$
p \leq F\left(\tau^{* *}\right)=G\left(\tau^{* *}\right)
$$

Proof: Equilibrium $\tau$ exists if and only if $\tau_{1} \leq \tau_{2}, \tau_{1}<3 \eta$, and $\tau_{2} \geq 2 \eta$. Suppose (12), and we have

$$
\begin{aligned}
\tau_{1} & =F^{-1}(p) \\
& \leq F^{-1}\left(F\left(\tau^{* *}\right)\right)=\tau^{* *}=G^{-1}\left(G\left(\tau^{* *}\right)\right) \\
& \leq G^{-1}(p)=\tau_{2},
\end{aligned}
$$

because $F(\tau)$ and $G(\tau)$ are increasing and decreasing with $\tau$, respectively. Therefore, $\tau_{1} \leq$ $\tau_{2}$. From this, it is also clear that $\tau_{1}<3 \eta$ and $\tau_{2} \geq 2 \eta$, because $\tau^{* *}$ lies between $2 \eta$ and $3 \eta$. Conversely, suppose that (12) does not hold. Then, we have

$$
\tau_{1}=F^{-1}(p)>\tau^{* *}>G^{-1}(p)=\tau_{2} .
$$

Therefore, $\tau_{1}>\tau_{2}$. No equilibrium $\tau$ exists.

Condition (8) is equivalent to $p \leq F\left(\tau^{* *}\right)$, that is, (12).

\section{Example of Equilibrium with a Poisson-distributed Warning}

We provide an example of equilibrium strategies with a Poisson-distributed warning, which satisfies monotonicity with respect to $t_{W}$ and $t_{i}$. First, we define $\tau_{0}^{*}, t^{m}$ and $m^{*}$ as follows.

Definition 2 Define $\tau_{0}^{*}$ such that

$$
\mu_{t}\left(E \mid t_{i}, t_{W}=0\right)=\frac{\exp (-g \eta)\left[\exp \left(g \tau_{0}^{*}\right)-1\right]}{\exp \left(g \tau_{0}^{*}\right)-\exp (-g \eta)} .
$$

Define $t^{m}$ such that

$$
\mu_{t}\left(E \mid t^{m}, t_{W}\right)=\frac{\exp (-g \eta)\left[\exp \left(g\left(\tau_{0}^{*}+(m+1) \varepsilon \eta\right)\right)-1\right]}{\exp \left(g\left(\tau_{0}^{*}+m \varepsilon \eta\right)-\exp (-g \eta)\right.},
$$

where $m$ is a nonnegative integer: $0,1,2,3, \ldots, t_{-1} \rightarrow \infty$, and $\varepsilon \in(0,1)$.

Define $m^{*}$ such that $\tau_{0}^{*}+m^{*} \varepsilon \eta<\bar{\tau}$ and $\tau_{0}^{*}+\left(m^{*}+1\right) \varepsilon \eta \geq \bar{\tau}$. 
Then, the following corollary shows such an equilibrium. In order to consider the case wherein investors receive both the public warning and the private signal $\left(t \geq \max \left\{t_{i}, t_{W}\right\}\right)$, we suppose $2 \eta+\tau^{*} \geq t_{W}$, which means that even if an investor receives the private signal in a very early period $\left(t_{i}=2 \eta\right)$, he also receives the public warning before he sells $\left(2 \eta+\tau^{*}\right)$.

Corollary 2 Suppose that a public warning is distributed as (3), and $2 \eta+\tau^{*}>t_{W}$. Then, at $t \geq \max \left\{t_{i}, t_{W}\right\}$, there exists an equilibrium such that an investor sells the asset at $T\left(t_{i}, t_{W}\right)=t_{i}+\tau_{0}^{*}+m \varepsilon \eta$ if $\tau_{0}^{*}+m \varepsilon \eta<\bar{\tau}, t_{i} \in\left[t^{m}, t^{m-1}\right)$, and $\varepsilon$ is sufficiently high such that at least one type of investor (type- $t_{i}$ ) is included in $\left[t^{m}, t^{m-1}\right.$ ) for all $m$. If $\tau_{0}^{*}+m \varepsilon \eta>\bar{\tau}$, the investor sells the asset at $T\left(t_{i}, t_{W}\right)=\tau_{0}^{*}+m^{*} \varepsilon \eta<t_{i}+\bar{\tau}$. In this equilibrium, the duration to hold the asset, $\tau\left(t_{i}, t_{W}\right)=\min \left\{\tau_{0}^{*}+m \varepsilon \eta, \tau_{0}^{*}+m^{*} \varepsilon \eta\right\}$ is nondecreasing with $t_{W}$ and nonincreasing with $t_{i}$.

Proof: In (14), $t^{m}$ decreases with $m$. This is because the right-hand side of (14) increases with $m$ when $\varepsilon \in(0,1)$ and that the left-hand side decreases with $t^{m}$ due to Lemma 2 . Since $t^{m}$ decreases with $m$, we can define Group- $m$ investors as those who receive the private signal at $t_{i} \in\left[t^{m}, t^{m-1}\right)$ for $m=0,1,2,3, \cdots$.

We start by examining the group least confident of being type- $E$ (the lowest $\mu_{i, t}\left(E \mid t_{i}, t_{W}\right)$ ) and denote it as Group $0(m=0)$. Suppose that investors choose $\tau_{0}^{*}$ if they receive the private signal very late, that is, at $t_{i} \in\left[t^{0}, \infty\right)$. The condition (5) is satisfied for $t_{i} \in\left[t^{0}, \infty\right)$, because (13) equalizes (5) when $t_{i}$ goes to infinity, and when $t_{i}<\infty$, the left-hand side of (13), $\mu_{t}\left(E \mid t_{i}, t_{W}\right)$, becomes larger than $(1+\exp (1)(1-\alpha) / \alpha)^{-1}$.

We move on to the $(m+1)$-th group least confident of being type- $E$, called Group $m$, and the marginal investor in Group $m-1\left(t^{m-1}\right)$ for $m=1,2, \ldots$ Investors in Group $m$ receive the private signal at $t_{i} \in\left[t^{m}, t^{m-1}\right)$. Suppose that investors in Group $m$ choose the strategy given by $\tau\left(t_{i}, t_{W}\right)=\tau_{0}^{*}+m \varepsilon \eta$. Then, the marginal investor in Group $m-1$, who receives the private signal at $t^{m-1}$, chooses $\tau\left(t_{i}, t_{W}\right)=\tau_{0}^{*}+(m-1) \varepsilon \eta$. The marginal investor in Group $m$, who receives the private signal $\eta$ period earlier, that is, at $t^{m-1}-\eta$, chooses $\tau\left(t_{i}, t_{W}\right)=\tau_{0}^{*}+m \varepsilon \eta$. The condition (5) is satisfied with equality for the strategy of the 
marginal investor in Group $m-1$, that is,

$$
\begin{aligned}
\mu_{t}\left(E \mid t^{m-1}, t_{W}\right) & =\frac{\exp (-g \eta)\left[\exp \left(g\left(\tau_{0}^{*}+m \varepsilon \eta\right)\right)-1\right]}{\exp \left(g\left(\tau_{0}^{*}+(m-1) \varepsilon \eta\right)-\exp (-g \eta)\right.} \\
& =\frac{\exp (-g \eta)\left[\exp \left(g \tau\left(t^{m-1}-\eta, t_{W}\right)\right)-1\right]}{\exp \left(g \tau\left(t^{m-1}, t_{W}\right)\right)-\exp (-g \eta)} .
\end{aligned}
$$

Investors in Group $m$ are more confident of being type- $E$ investors than this marginal investor in Group $m-1$ who receives the private signal at $t^{m-1}: \mu_{t}\left(E \mid t_{i}, t_{W}\right)>\mu_{t}\left(E \mid t^{m-1}, t_{W}\right)$ for $t_{i} \in\left[t^{m}, t^{m-1}\right)$. The left-hand side of (5) increases, and hence, the condition (5) is also satisfied for the strategies of all Group $m$ investors.

Recall that the bubble duration ceiling is determined by the exogenous burst, $\bar{\tau}$. As $m$ increases, the asset can be held for a longer duration, as is clearly illustrated by $\tau\left(t_{i}, t_{W}\right)=$ $\tau_{0}^{*}+m \varepsilon \eta$. Therefore, if $\tau_{0}^{*}+m \varepsilon \eta \geq \bar{\tau}$, investors should not hold the asset until $t_{i}+\tau_{0}^{*}+m \varepsilon \eta$, and $T\left(t_{i}, t_{W}\right)=\tau_{0}^{*}+m^{*} \varepsilon \eta<t_{i}+\bar{\tau}$ can become an equilibrium strategy, where $m^{*}$ satisfies $\tau_{0}^{*}+m^{*} \varepsilon \eta<\bar{\tau}$ and $\tau_{0}^{*}+\left(m^{*}+1\right) \varepsilon \eta \geq \bar{\tau}$. To see if this satisfies (5), we examine two cases. The first is the transition from $\tau_{0}^{*}+\left(m^{*}-1\right) \varepsilon \eta$ to $\tau_{0}^{*}+m^{*} \varepsilon \eta$. It is obvious that (5) is satisfied (shown earlier). Second, investors in Group $m$ for $m \geq m^{*}$ face

$$
\begin{aligned}
\mu_{t}\left(E \mid t^{m}, t_{W}\right) & =\frac{\exp (-g \eta)\left[\exp \left(g\left(\tau_{0}^{*}+(m+1) \varepsilon \eta\right)\right)-1\right]}{\exp \left(g\left(\tau_{0}^{*}+m \varepsilon \eta\right)-\exp (-g \eta)\right.} \\
& \geq \frac{\exp (-g \eta)\left[\exp \left(g\left(\tau_{0}^{*}+m \varepsilon \eta\right)\right)-1\right]}{\exp \left(g\left(\tau_{0}^{*}+m \varepsilon \eta\right)-\exp (-g \eta)\right.} \\
& \geq \frac{\exp (-g \eta)\left[\exp \left(g\left(\tau_{0}^{*}+m^{*} \varepsilon \eta\right)\right)-1\right]}{\exp \left(g\left(\tau_{0}^{*}+m^{*} \varepsilon \eta\right)\right)-\exp (-g \eta)} \\
& =\frac{\exp (-g \eta)\left[\exp \left(g \tau\left(t^{m}-\eta, t_{W}\right)-1\right]\right.}{\exp \left(g \tau\left(t^{m}, t_{W}\right)\right)-\exp (-g \eta)}
\end{aligned}
$$

and hence, (5) is satisfied as well.

Finally, we show that $\tau\left(t_{i}, t_{W}\right)=\min \left\{\tau_{0}^{*}+m \varepsilon \eta, \tau_{0}^{*}+m^{*} \varepsilon \eta\right\}$ is nondecreasing with $t_{W}$ and nonincreasing with $t_{i}$. The right-hand side of (14) increases with $m$. The left-hand side of $(14)$, that is, $\mu_{t}\left(E \mid t_{i}, t_{W}\right)$, is nondecreasing with $t_{W}$ and nonincreasing with $t_{i}$ due to Lemma 2. Therefore, $m$ is nondecreasing with $t_{W}$ and nonincreasing with $t_{i}$, and hence, $\tau\left(t_{i}, t_{W}\right)=\max \left\{\tau_{0}^{*}+m \varepsilon \eta, \tau_{0}^{*}+m^{*} \varepsilon \eta\right\}$ is nondecreasing with $t_{W}$ and nonincreasing with $t_{i}$. 


\section{References}

Abreu, D., and M. K. Brunnermeier, "Synchronization Risk and Delayed Arbitrage," Journal of Financial Economics 66(2-3), 2002, 341-360.

Abreu, D., and M. K. Brunnermeier, "Bubbles and Crashes," Econometrica 71(1), 2003, 173-204.

Allen, F., and G. Gordon, "Churning Bubbles," Review of Economic Studies 60(4), 1993, 813-836.

Allen, F., S. Morris, and A. Postlewaite, "Finite Bubbles with Short Sale Constraints and Asymmetric Information,” Journal of Economic Theory 61(2), 1993, 206-229.

Allen, F., and D. Gale, "Bubbles and Crises," Economic Journal 110, January 2000, 236-255.

Bernheim, D., B. Peleg, and M. D. Whinston, "Coalition-Proof Nash Equilibria I: Concepts," Journal of Economic Theory 42(1), 1987, 1-12.

Borio, C., and P. Lowe, "Asset Prices, Financial and Monetary Stability: Exploring the Nexus.” BIS Working Papers 114, 2002.

Brunnermeier, M. K., Asset Pricing under Asymmetric Information: Bubbles, Crashes, Technical Analysis, and Herding. Oxford: Oxford University Press, 2001.

Brunnermeier, M. K. and J. Morgan, "Clock Games: Theory and Experiments," Games and Economic Behavior 68(2), 2010, 532-550.

De Long, J. B., A. Shleifer, L. H. Summers, and R. J. Waldmann, "Noise Trader Risk in Financial Markets," Journal of Political Economy 98(4), 1990, 703-738.

Doblas-Madrid, A., 2012, "A Robust Model of Bubbles with Multidimensional Uncertainty," Econometrica 80(5), 2012, 1845-1893.

Harrison, J. M., and D. M. Kreps, "Speculative Investor Behavior in a Stock Market with Heterogeneous Expectations," Quarterly Journal of Economics 92(2), 1978, 323-336.

Kindleberger, C. P., and R. Aliber, Manias, Panics, and Crashes: A History of Financial Crises, 6th Edition. New Jersey: John Wiley \& Sons, Inc., 2011.

Mishkin, F. S., Monetary Policy Strategy. Cambridge: MIT Press, 2007.

Moreno, D., and J. Wooders, "Coalition-proof Equilibrium," Games and Economic Be- 
havior 17(1), 1996, 80-112.

Morris, S., A. Postlewaite, and H. Shin, "Depth of Knowledge and the Effect of Higher Order Uncertainty," Economic Theory 6(3), 1995, 453-467.

Okina, K., M. Shirakawa, and S. Shiratsuka, "The Asset Price Bubble and Monetary Policy: Japan's Experience in the Late 1980s and the Lessons," Monetary and Economic Studies 19(S-1), 2001, 395-450.

Samuelson, P. A., "An Exact Consumption-Loan Model of Interest with or without the Social Contrivance of Money," Journal of Political Economy 66, February1958, 467-482.

Scheinkman, J. A., and W. Xiong, "Overconfidence and Speculative Bubbles," Journal of Political Economy 111(6), 2003, 1183-1219.

Temin, P., and H. Voth, "Riding the South Sea Bubbles," American Economic Review 94(5), 2004, 1654-1668.

Tirole, J., "Asset Bubbles and Overlapping Generations," Econometrica 53(6), 1985, $1499-1528$.

White, W. R., "Is Price Stability Enough?" BIS Working Papers 205, April 2006. 


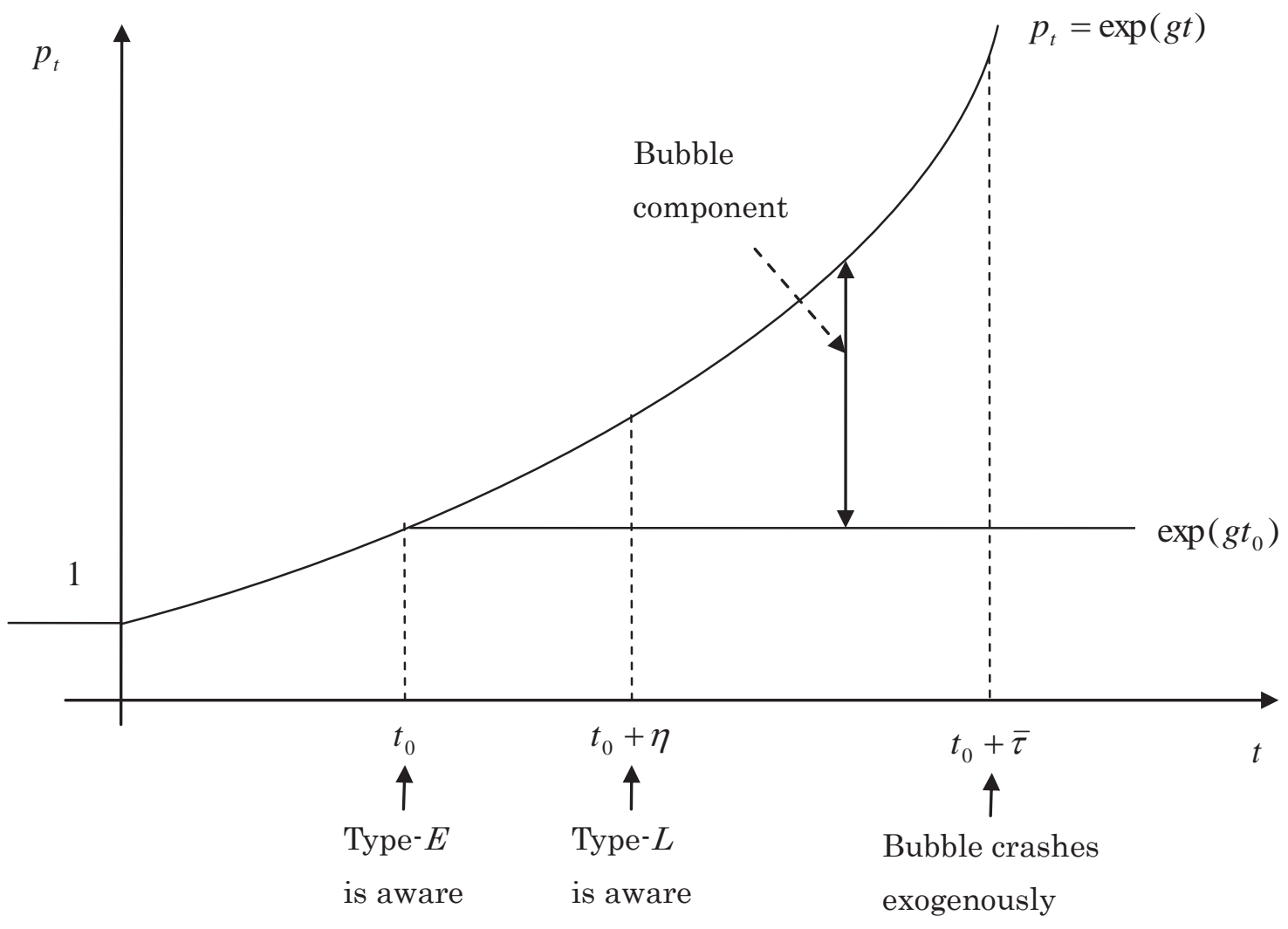

Figure 1: A Simplified Model of Abreu and Brunnermeier (2003) 


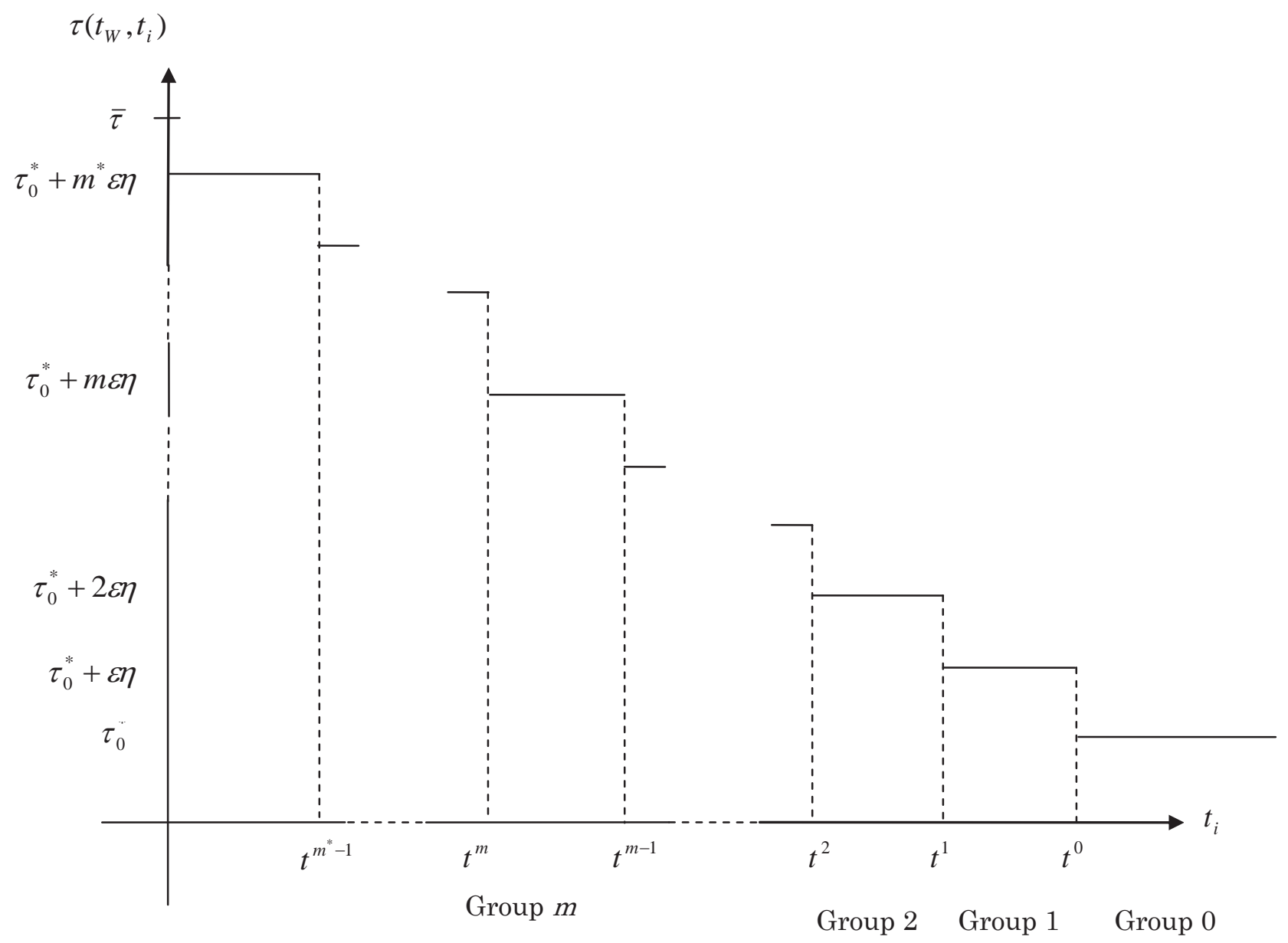

Figure 2: Monotonic Example of Equilibrium with a Poisson-distributed Warning 


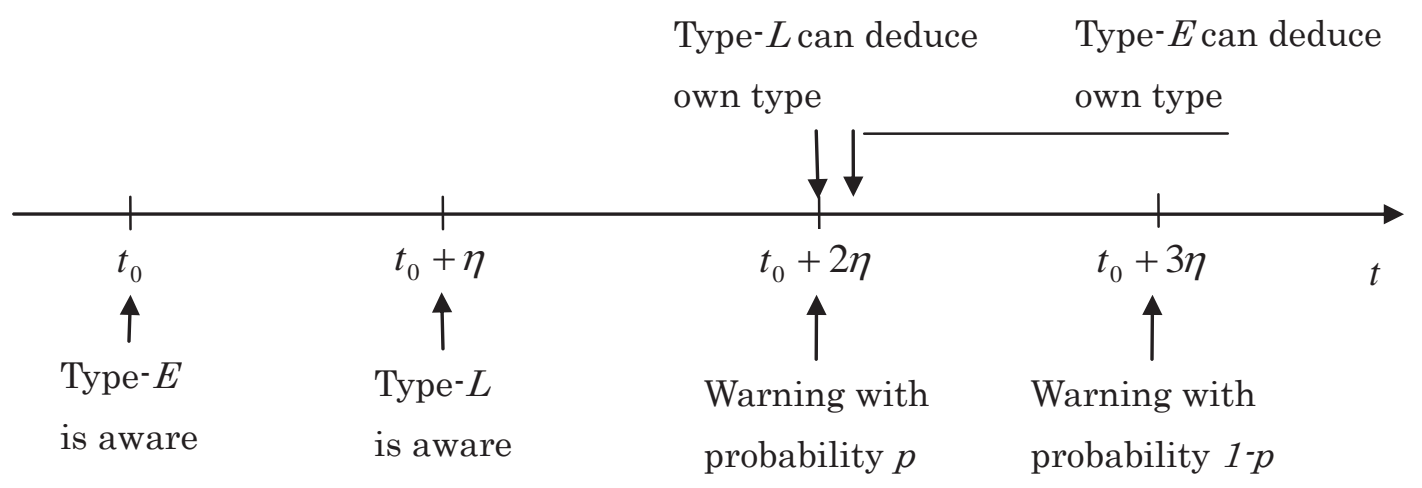

Figure 3: Two-period Warning 